\title{
1 Softening and consolidation around seabed pipelines: Centrifuge modelling
}

2 Manuscript revised and submitted to Géotechnique on 09/03/2017

3 Michael L. COCJIN (BEng, MEng) (corresponding author)

4 Centre for Offshore Foundation Systems - M053,

5 A node of ARC Centre for Geotechnical Science and Engineering

6 University of Western Australia

735 Stirling Highway, Crawley, Perth, WA 6009, Australia

$8 \quad$ Tel: +61 86488 3995, Fax: +61 864881044

9 Email: michael.cocjin@ research.uwa.edu.au

10 Susan M. GOURVENEC (BEng, PhD)

11 Centre for Offshore Foundation Systems, UWA

12 A node of the ARC Centre for Geotechnical Science and Engineering

13 Email: susan.gourvenec@uwa.edu.au

14 David J. WHITE (MA, MEng, PhD)

15 Centre for Offshore Foundation Systems, UWA

16 A node of the ARC Centre for Geotechnical Science and Engineering

17 Email: david.white@uwa.edu.au 


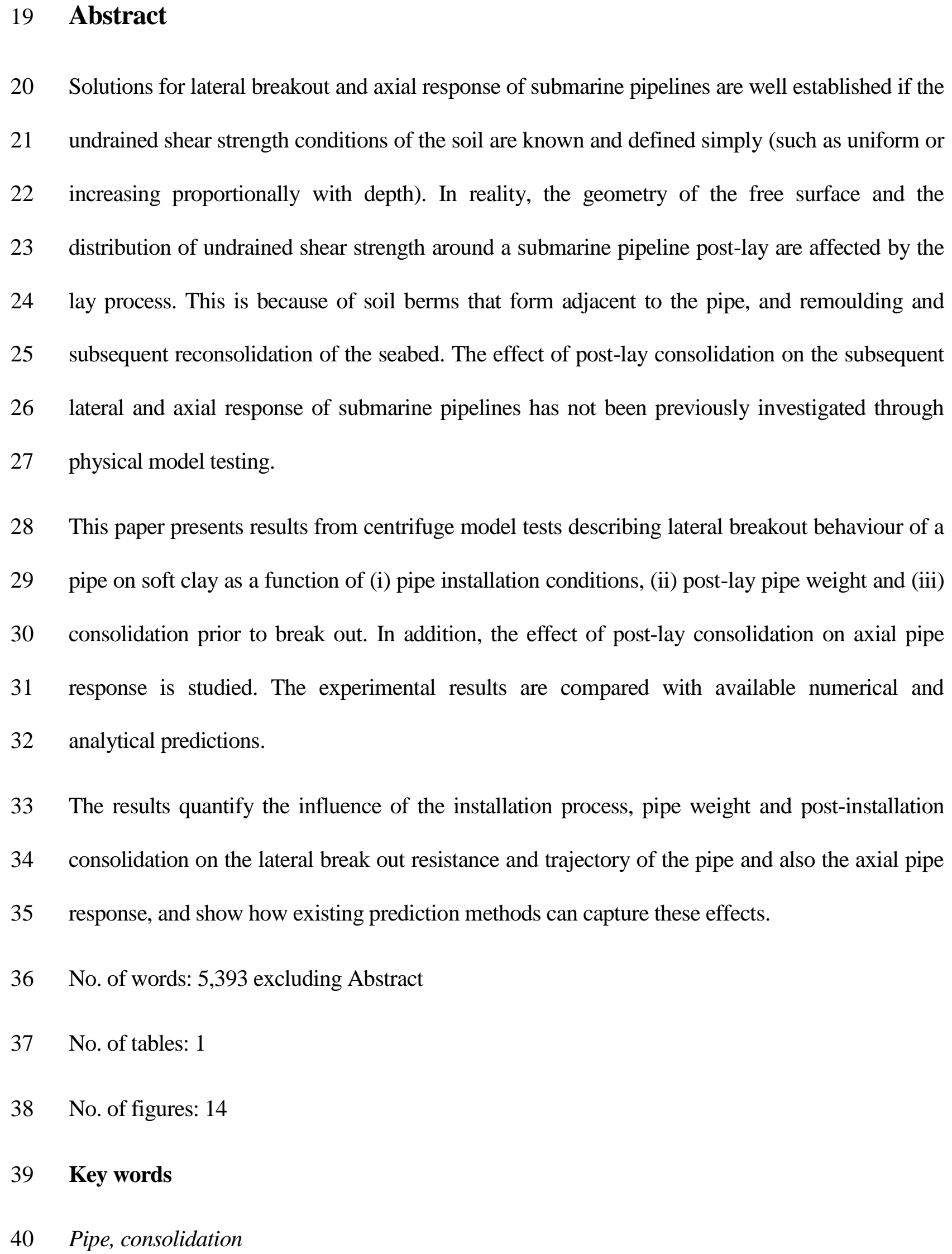

20 Solutions for lateral breakout and axial response of submarine pipelines are well established if the 21 undrained shear strength conditions of the soil are known and defined simply (such as uniform or 22 increasing proportionally with depth). In reality, the geometry of the free surface and the 23 distribution of undrained shear strength around a submarine pipeline post-lay are affected by the 24 lay process. This is because of soil berms that form adjacent to the pipe, and remoulding and 25 subsequent reconsolidation of the seabed. The effect of post-lay consolidation on the subsequent 26 lateral and axial response of submarine pipelines has not been previously investigated through 27 physical model testing.

28 This paper presents results from centrifuge model tests describing lateral breakout behaviour of a 29 pipe on soft clay as a function of (i) pipe installation conditions, (ii) post-lay pipe weight and (iii) 30 consolidation prior to break out. In addition, the effect of post-lay consolidation on axial pipe 31 response is studied. The experimental results are compared with available numerical and 32 analytical predictions.

33 The results quantify the influence of the installation process, pipe weight and post-installation 34 consolidation on the lateral break out resistance and trajectory of the pipe and also the axial pipe 35 response, and show how existing prediction methods can capture these effects.

36 No. of words: 5,393 excluding Abstract

37 No. of tables: 1

38 No. of figures: 14

$39 \quad$ Key words

40 Pipe, consolidation 


\section{Introduction}

42 Networks of in-field pipelines are a central component of offshore subsea developments, creating

43 an increasing need to better understand pipeline behaviour during installation and operation to 44 improve design outcomes.

45 Offshore in-field pipelines are generally laid directly on the seabed, and left unburied. The pipe 46 partially embeds into the seabed during the laying process due to its self-weight and dynamic lay 47 effects. The lay process submits the soil to disturbance and remoulding, resulting in softening of 48 the seabed deposit surrounding the newly installed pipe. However, after laying, the vertical load 49 on the seabed is reduced to the static pipe weight, and the soil around the pipe consolidates under 50 that load. For the soft, normally consolidated soils typically found offshore, this consolidation 51 process leads to an increase in the strength of the seabed deposit surrounding the pipeline.

52 The dominant operational forces on deepwater in-field pipelines are from internal temperature 53 and pressure, rather than external hydrodynamic loading. High pipeline temperature causes 54 longitudinal expansion, which is opposed by axial resistance between the pipe and the seabed 55 (Bruton et al. (2008)). Excessive compressive forces arising from thermal expansion or high designated locations to relieve the thermal and pressure-induced loading (Sinclair et al. (2009)).

60 Lateral buckles along the pipeline can significantly influence the global response of the flowline 61 including the attached infrastructure such as the pipeline end termination or manifolds 62 (PLET/PLEMs).

63 In recent years, axial and lateral pipe-soil interactions have been studied extensively by 64 researchers, with a particular focus on the undrained conditions that generally prevail during 
lateral pipe movements on fine-grained soils. Solutions for penetration, axial and lateral responses using analytical approaches (Randolph and Houlsby (1984), Murff et al. (1989), Martin and Randolph (2006), Randolph and White (2008), Martin and White (2012), Randolph et al. (2012)) and finite element analysis (FEA) both through small-strain (Aubeny et al. (2005), Merifield et al. (2008), Merifield et al. (2009), Krost et al. (2011), Chatterjee et al. (2014)) and large-deformation approaches (Wang et al. (2010), Chatterjee et al. (2012c), Chatterjee et al. (2012a), Chatterjee et al. (2012b), Chatterjee et al. (2013)) are plenty, and can provide a prediction of pipe axial or lateral breakout capacity if the undrained shear strength conditions of the soil are known and defined simply (such as uniform or increasing linearly with depth). Experimental investigations into pipeline behaviour have also been performed at large scale and at reduced scale in a centrifuge, as reported by Bruton et al. (2006), Bruton et al. (2008), Cheuk et al. (2007), Dingle et al. (2008) and Cardoso and Silveira (2010). These studies have led to empirical expressions for the unconsolidated lateral breakout resistance and the subsequent steady residual resistance, simulating a model pipe that breaks out immediately after installation.

In reality, the geometry of the free surface and the distribution of the undrained shear strength around a pipeline post-lay can be significantly affected by the remoulding process during the pipe laying. The axial and lateral resistance subsequently available between the pipeline and the soil is influenced by consolidation of the soil around the pipeline that takes place between the laying process and when the pipeline operation starts. The resulting changes in soil strength and pipesoil resistance are the subject of this paper. Results of a suite of geotechnical centrifuge tests designed to explore the changes in axial and lateral breakout resistances resulting from installation disturbance and reconsolidation in soft clay are reported and interpreted. 


\section{Experimental program}

88 Apparatus

89 Centrifuge and actuation

90 The tests were carried out in the $1.8 \mathrm{~m}$ radius beam centrifuge at the Centre for Offshore 91 Foundation Systems at the University of Western Australia (Randolph et al. (1991)). The 92 platform of the rotating arm holds a strongbox with dimensions $650 \mathrm{~mm}$ by $390 \mathrm{~mm}$ in plan and $93325 \mathrm{~m}$ deep with a maximum payload of $200 \mathrm{~kg}$ at $200 \mathrm{~g}$. Box-mounted actuators control vertical 94 and horizontal loads or displacements of the model through an instrumented loading arm. In95 house software is used for control and data acquisition during tests (Gaudin et al. (2009), De 96 Catania et al. (2010)). The tests reported in this chapter were carried out at $25 \mathrm{~g}$.

\section{$97 \quad$ Model pipe}

98 A schematic drawing of the model pipe is shown in Figure 1(a-b). The model pipe has a 99 diameter of $30 \mathrm{~mm}, 150 \mathrm{~mm}$ long, representing a diameter of $D=0.75 \mathrm{~m}$ and a length of $L=3.75$ $100 \mathrm{~m}$ at prototype scale. The pipe was fabricated from a solid piece of aluminium with sand glued to 101 the bottom half to provide a rough pipe-soil interface.

102 The pipe section was instrumented with 6 pore pressure transducers (PPTs) located along the 103 length of the underside of the pipe at the invert and at the sides between the pipe axis and invert. 104 The arc length between the invert and side PPTs is $15.7 \mathrm{~mm}(0.39 \mathrm{~m}$, prototype scale), forming a 105 central angle of $\theta_{P P T}=60^{\circ}$.

106 Soil sample

107 To make the model seabed, kaolin clay slurry with water content of $120 \%$ (or twice its liquid 108 limit) was mixed for 2 days in a vacuum. The slurry was poured into the strongbox over a sand 
109 drainage layer covered with a geotextile. The sample was consolidated in-flight, continuously for 11065 hours at the test acceleration of $25 \mathrm{~g}$ to achieve a normally consolidated deposit. Full 111 consolidation was verified via a linearly increasing shear strength profile with depth obtained 112 from ball penetrometer tests. The top of the sample was then scraped to provide a flat and smooth 113 working surface, removing 2-3 mm of clay in the process, leading to a nominal non-zero mudline 114 strength.

115 A miniature ball penetrometer (Chung and Randolph (2004), Low et al. (2007), Colreavy et al. 116 (2016)) with diameter of $15 \mathrm{~mm}(0.375 \mathrm{~m}$, prototype scale) was used to measure the shear 117 strength profile of the soil sample. The ball penetrometer was penetrated into the soil sample at a 118 rate of $1 \mathrm{~mm} / \mathrm{s}$ to ensure undrained conditions (Randolph and Hope (2004)). The first penetration 119 was carried out up to a depth of $88 \mathrm{~mm}$ ( $2.2 \mathrm{~m}$ prototype scale), after which 10 cycles of 120 penetration and extraction were carried out between depths $24 \mathrm{~mm}(0.6 \mathrm{~m})$ and $70 \mathrm{~mm}(1.75 \mathrm{~m})$ 121 before the penetrometer was completely extracted.

122 The penetration resistance measured by the ball penetrometer, qball was corrected for unequal 123 pore pressure and overburden pressure following the expression defined by Chung and Randolph 124 (2004):

$\left.q_{m}=q_{\text {ball }}-\left[\sigma_{v 0}-u_{0}(1-\alpha)\right] A_{s} / A_{p}\right]$

125 where $q_{m}$ is the net penetration resistance, $\sigma_{v 0}$ is the in situ total overburden stress, $u_{0}$ is the 126 hydrostatic pressure, $A_{\mathcal{S}} / A_{P}$ is the ratio of the shaft to the projected area of the ball penetrometer, 127 and parameter $\alpha$ is the net area ratio of the load cell core to the shaft area (equivalent to 0.85 for 128 the tests considered here).

129 The undrained shear strength, $s_{u}$, is back calculated from the net penetration resistance, $q_{m}$ as: 


$$
s_{u}=\frac{1}{N_{\text {ball }}}\left(q_{m}-\frac{F_{\text {buoy }}}{A_{p}}\right)
$$

130 where $F_{\text {buoy }}$ is the soil buoyancy force on the ball penetrometer and $N_{\text {ball }}$ is the constant ball 131 penetrometer factor, assumed equivalent to 10.5, typical for penetrometer penetration tests (Low 132 et al. (2007), Colreavy et al. (2016)).

133 The in situ and remoulded shear strength profiles derived from the cyclic ball penetrometer test are shown in Figure 2(a) and Figure 2(b), respectively. The shear strength profile was calculated 135 by adopting a constant value for $N_{\text {ball }}$ over the entire sample depth, which introduces minimal 136 near-surface error for a normally consolidated soil (Gourvenec et al. (2009), Low et al. (2010)). 137 The resulting intact, in situ, undrained shear strength, $s_{u 0}$ was approximated to increase linearly 138 with depth, $z$ within $0<z(\mathrm{~mm})<40(1 \mathrm{~m}$ depth in prototype scale) as:

$$
s_{u 0}=s_{u m}+k z
$$

139 with mudline strength of $s_{u m}=0.1 \mathrm{kPa}$, and strength gradient of $k=0.7 \mathrm{kPa} / \mathrm{m}$. Degradation in 140 shear strength due to remoulding during the cyclic phase of the ball penetrometer test shows a 141 final remoulded strength of the soil, $\delta_{\text {rem }}=0.47$ (Figure 2(b)), where $\delta_{\text {rem }}$ is defined as the ratio of 142 the remoulded to intact strength as measured halfway of the cycled route $(z=47 \mathrm{~mm}$, or $1.175 \mathrm{~m}$ 143 in prototype scale). The evolution of the remoulded shear strength with loading cycle shown in 144 Figure 2(b) can be captured by the commonly-used exponential degradation curve pattern (Einav 145 and Randolph (2005)) given by:

$$
\frac{s_{u, c y c}}{s_{u 0}}=\delta_{r e m}+\left[1-\left(\delta_{r e m}\right)\right] e^{\frac{-3(N-0.5)}{N_{95}}}
$$

146 where $s_{u, c y c}$ is the strength measured during the cyclic phase of the ball penetrometer test, and $N_{95}$ $147=2.5$ is the number of cycles required to achieve $95 \%$ of $\delta_{\text {rem }}$ from the intact strength. 
148 The moisture content profile of the soil model was also determined from core samples taken after

149 all the tests, where an average effective unit weight, $\gamma^{\prime}=5.7 \mathrm{kN} / \mathrm{m}^{3}$ over the depth of the soil

150 model was obtained.

151 Pipe testing programme

152 A series of pipe tests was carried out, as summarised in Table 1. Each test involved initial 153 penetration of the pipe to a depth equal to half the diameter $(w / D=0.5)$ to simulate the 154 installation or pipe 'laying' process. The pipe was then unloaded to an operative vertical load,

\section{Undrained penetration response}

168 The influence of installation or pipe 'laying' method on the pipe penetration response is presented 169 in Figure 3. 
170 The pipe penetration resistance is expressed in terms of the pipe vertical bearing pressure per unit

171 length, $V / D$, and normalised vertical penetration resistance, $V / D s_{u}$ o. Profiles with pipe invert 172 embedment, $w / D$ for different tests are shown in Figure 3(a) and Figure 3(b), respectively. An 173 inset figure in Figure 3(a) shows the pipe displacements during penetration, indicating the 174 trajectory of the monotonically and cyclically penetrated pipe cases.

175 The monotonic penetration response is highly repeatable as shown in Figure 3(a-b). A linear 176 increase in $V / D$ with depth is observed in these cases, with the response dominated by the linear 177 variation of the undrained shear strength with depth (Equation 3). The increase in $V / D s_{u} 0$ with 178 depth on monotonic cases is compared against existing numerical solutions (Aubeny et al. (2005) 179 and Chatterjee et al. (2012a), based on small-strain and large deformation finite element analyses, 180 respectively) as shown in Figure 3(b). At $w / D=0.5$, a normalised vertical penetration resistance 181 of $V_{\max } / D s_{u 0} \sim 10.5$ is recorded in the centrifuge tests close to the value derived by Aubeny et al. 182 (2005). The numerical solutions presented in Figure 3(b) considers $V / D s_{u 0}$ as a sum of the soil 183 resistance and a component due to buoyancy as the pipe becomes embedded within the soil, 184 expressed as:

$$
\frac{V}{D s_{u 0}}=N_{c}+N_{b}\left(\frac{\gamma^{\prime} w}{s_{u 0}}\right)
$$

185 where the soil bearing factor, $N_{c}$ reflects the component of the soil resistance, typically expressed 186 in terms of a power law function of the penetration depth (Aubeny et al. (2005)). The pipe 187 buoyancy resistance, $N_{b} \gamma^{\prime} w$ increases with depth as shown in Figure 3(a), where $N_{b}$ is the self188 weight factor given by:

$$
N_{b}=f_{b} \frac{A_{s}}{D w}
$$


$189 N_{b}$ is proportional to the potential energy needed to lift the displaced soil with a nominal weight 190 of $A_{s} \gamma^{\prime}$ to the top of the pre-existing heave next to the pipe, with $A_{s}$ being the cross-sectional area 191 of the embedded pipe. When the displaced soil forms heave mounds and alters the geometry of 192 the soil next to the pipe, the soil buoyancy is enhanced through the factor $f_{b}$ where an $f_{b}=1$ 193 corresponds to no heave, following Archimedes' principle (buoyancy force being equal to the 194 weight of the displaced fluid). The effects of buoyancy and the changes in soil geometry and 195 development of soil heave during penetration are not considered in the upper bound plasticity 196 solution presented by Randolph and White (2008) which assumes a flat seabed surface, resulting 197 in lower $V / D s_{u 0}$ estimates compared to the values observed in the current centrifuge tests (Figure 198 3(b))

199 Existing solutions do not capture the more complicated penetration response exhibited by cyclically penetrated pipe (Figure 3(b)). The cyclic penetration of the pipe mobilised a lower $V / D$ and $V / D s_{u 0}$ compared to monotonically penetrated pipes. The decrease in penetration resistance during the oscillating movements of the pipe is reflected by the elevated pore water pressure in the surrounding soil shown in Figure 3(c) which plots the excess pore water pressure at the pipe invert as a ratio of the pipe vertical bearing pressure per unit length, $\Delta u_{\text {inv }} /(V / D)$.

\section{Post-lay consolidation response}

Figure 4(a) presents the variation with time, $t$ (prototype scale) of the pore water pressure, $u$, relative to a datum of zero prior to penetration of the pipe, for each of the PPTs installed in the model pipe during penetration, post-lay consolidation, and lateral loading in test R2CU. The average pore pressure recorded by the invert and side PPTs are denoted as $u_{i n v}$ and $u_{\text {side }}$, respectively. In general, pore pressure around the pipe increases when the soil is loaded, as $V / D$ increases, and when remoulded via the simulated dynamic lay process. However, pore pressure reduces at constant $V / D$ during post-lay consolidation, during which time the excess pore water 
213 pressure at the pipe invert, $\Delta u_{i n v}$ which is equivalent to the difference between $u_{0}$ and the invert

214 pore water pressure, $u_{i n v}$ as shown in Figure 4(b), dissipates.

215 The change in excess pore pressure at the pipe invert level, normalised by the maximum value 216 recorded under the maximum vertical load, is shown in Figure 5(a) for various tests, with the 217 time axis zeroed at the moment when the reduction in vertical load is complete. The subsequent 218 unloading from $V_{\max }$ to $V_{o p}$ is evident in a concurrent drop in excess pore pressure at the invert 219 level.

220 The influence of pipe weight on the post-lay dissipation behaviour of the invert excess pore 221 pressure is shown more clearly in Figure 5(b) which plots $\Delta u_{\text {inv }}$ relative to $V / D$ against time 222 factor, $T=c_{v} t / D^{2}$ with $c_{v}$ being the vertical coefficient of consolidation. At the start of consolidation, the excess pore pressure is higher relative to the applied stress for increasing unloading ratio, $V_{\max } / V_{\text {op. }}$. The additional excess pore water pressure generated by the cyclic penetration of the pipe is also evident in this figure (compare RemR4CU against R4CU in Figure $\mathbf{5}(\mathbf{b}))$.

Figure 5(c) shows that the post-lay dissipation behaviour in pipe cases with $V_{o p}>0.5 \cdot V_{\max }$ (R1CU and R2CU) is close to the solutions derived from elasto-plastic (Chatterjee et al. (2012c)), and elastic (Krost et al. (2011)) small-strain FEA models. For pipes at a higher overloading ratio and with remoulding during installation, the additional excess pore pressure created by these effects leads to a higher response. However, with dissipation, all responses converge towards the theoretical solution. The only exception is R8CU, which is an outlier. For this high overloading ratio, only small level of remnant excess pore pressure is needed at the invert to cause a high value of $\left(\Delta u / \Delta u_{i n i}\right)_{i n v}$.

The dissipation of excess pore pressure during post-lay consolidation results in an increase in effective stress in the soil around the pipe. The effective stress increase can be illustrated by 
237 defining an effective contact enhancement factor, $\zeta$ given by the ratio of the effective normal 238 force, $N^{\prime}$ acting around the pipe-soil contact and the pipeline submerged weight per unit length, $V$ 239 (White and Randolph (2007), Krost et al. (2011)) as:

$$
\zeta^{\prime}=\frac{N^{\prime}}{V}
$$

240 At full consolidation (when the excess pore pressure is completely dissipated), the effective stress 241 is equal to the total stress around the pipe. A total force, $N$ can be obtained by summing the 242 normal contact stresses over the pipe-soil contact perimeter, $p$ and this force exceeds the pipeline 243 submerged weight per unit length, $V$ due to a 'wedging' effect around the curved pipe surface 244 (Figure 1(c)). The ratio $\zeta=N / V$ was derived by White and Randolph (2007) following the elastic 245 solution for a line load acting on a half-space, assuming that the normal stress on the pipe wall 246 varies with $\cos \theta$, where $\theta$ is the inclination from the vertical. $\zeta=N / V$ can then be obtained as:

$\zeta=\frac{N}{V}=\frac{2 \sin \theta}{\theta+\sin \theta \cos \theta}$ 8

247 where $\cos \theta=1-2(w / D)$. Through Equation 8, the total force, $N$ acting on the pipe with 248 embedment of $w=0.5 D$ is $1.27 \mathrm{~V}$.

249 The effective force, $N^{\prime}$ in Equation 7 is determined following the principle of effective stress as:

$$
N^{\prime}=N-p \Delta \bar{u}
$$

250 where $\Delta \bar{u}$ is the average excess pore pressure around the pipe, obtained in this case by linearly 251 interpolating the recorded excess pore pressures at the pipe invert $\left(\Delta u_{\text {inv }}\right)$, the side PPTs $\left(\Delta u_{\text {side }}\right)$, 252 and the zero pore pressure at the edge of the pipe and soil surface.

253 The distribution of the total radial stress, $\sigma_{r}$ and the interpolated $\Delta u$ during consolidation, 254 normalised by the prescribed vertical bearing pressure, $V / D$ is shown in Figure 6(a) and Figure 
6(b) for tests R4CU_AX and RemR4CU, respectively. Figure 6(a) also includes the distribution 4

5

6

7

8

9

of $\Delta u$ around the pipe in test R4UU_AX just before the pipe was displaced axially. These results are converted to the effective contact enhancement factor, $\zeta$ (Equation 7), varying with time factor, $T=c_{v} t / D^{2}$ in Figure 6(c) where the vertical coefficient of consolidation, $c_{v}$ ( $\mathrm{m}^{2} /$ year) was assumed to vary with stress (in $\mathrm{kPa}$ ), via the increase in mean effective stress at the pipe-soil contact, $N^{\prime} / p$ through the form $c_{v}=\left(0.3+0.16 N^{\prime} / p\right)^{0.47}($ Cocjin et al. $(2014))$.

261 Figure 6(c) shows that the elastic small-strain FEA solution by Krost et al. (2011) matches the increase in $\zeta^{\prime}$ with time for the case without vertical unloading (R1CU). In this case, the average excess pore pressure and the effective stress have equal contribution to the total stress immediately after vertical unloading, with the effective stress eventually increasing to total stress with the dissipation of the excess pore pressure. The increase in $\zeta$ with time can be expressed in a form given by Equation 10 as:

$$
\zeta^{\prime}=\zeta+\left(\frac{\zeta_{U U}-\zeta}{1+\left(T / T_{50}\right)^{m}}\right)
$$

267 where $\zeta$ (Equation 10) and $\zeta_{U U}$ are the fully consolidated $(T \rightarrow \infty)$ and unconsolidated $(T \sim 0)$ 268 undrained effective contact enhancement factors.

269 In Equation 10, $T_{50}$ is the time factor when $50 \%$ of the increase in $\zeta$ has occurred and $m$ is a 270 constant. Equation 10 is plotted in Figure 6(c) using $m=1.05$, and $T_{50}=0.135$ suggested for 271 rough pipe with embedment of $w=0.5 D$ (Chatterjee et al. (2012c)), and matches well the 272 measured trends.

273 The unconsolidated undrained effective contact enhancement factor, $\zeta_{U U}$ reduces with increasing 274 overload ratio, and is reduced further for the case with remoulding during pipe penetration (case 275 RemR4CU). This is because the overloading and remoulding processes both create additional 
excess pore pressure, meaning that initially a lower portion of the pipe weight is carried by effective stress. After full dissipation, however, the effective contact enhancement factor returns expressed as:

$$
\frac{H_{a x}}{V}=\zeta^{\prime} \tan \delta
$$

295 where $\delta$ is the pipe-soil friction angle. Using the excess pore pressure prior to axial loading, 296 Equation 11 provides a good prediction to the observed axial residual resistance on both the 
consolidated and unconsolidated cases, assuming a pipe-soil friction angle of $\delta=27.5^{\circ}$, which is

typical for kaolin at low stresses (Hill et al. (2012)).

\section{Lateral load-displacement response}

\section{Installation and post-lay consolidation effects}

301 The effect of post-lay consolidation and pipe 'laying' method on the lateral load-displacement 302 response is shown in Figure 8(a) and Figure 8(b) which plot the normalised lateral resistance, $303 H / D s_{u 0}$ and lateral friction factor, $H / V$ against the normalised lateral displacement, $x / D$ for tests 304 with $V_{o p} / V_{\max }=0.25$ (R4 series). $V / D s_{u 0}$ and $w / D$ during the lateral displacement of the pipe are 305 correspondingly provided in Figure 8(c) and Figure 8(d). Although the tests took place with a 306 constant simulated pipe weight, $V / D s_{u 0}$ increases as the pipe rises, reflecting the reduction in in 307 situ soil strength at the pipe invert level.

308 The lateral response after post-lay consolidation exhibited higher resistance than the case without 309 post-lay consolidation (compare R4CU and R4UU in Figure 8(a-b)). An immediate peak was 310 recorded during lateral breakout following consolidation, similar to the observations made on the 311 axial breakout response shown in Figure 7(a-b). An improvement in lateral resistance due to 312 consolidation is observed within $\sim 0.6 D$ lateral distance from the as-laid location (Figure 8(a313 b)). The breakout resistance is 1.8 times greater with post-lay consolidation than without, after 314 which the lateral resistance $\left(H / D s_{u 0}\right.$ and $\left.H / V\right)$ on both the consolidated and unconsolidated cases 315 converge to a similar value as the pipe moves further away from the as-laid position, 316 encountering soil unaffected by the post-lay consolidation. The gain in lateral resistance due to 317 post-lay consolidation is also higher for the pipe that was cyclically installed than in the pipe that 318 followed monotonic penetration (compare R4CU against RemR4CU in Figure 8(a-b)). Cyclic 319 remoulding of soil during pipe laying also created a wider zone of strengthened soil, where 320 enhancement of resistance can be observed up to $0.75 D$ lateral distance from the installation 
location (although the test was terminated shortly afterwards). Cyclic remoulding of soil during pipe laying led to elevated levels of excess pore pressure (Figure 3(c)) that consequently resulted in a greater reduction in moisture content and therefore strengthening after dissipation.

The observed differences in breakout resistance are consistent with the excess pore pressure recorded at the PPT on the rear side of the pipe, $\Delta u_{\text {rear }}$ shown in Figure 8(e). Higher negative pore pressure is observed for the higher breakout resistance, but in all cases the excess pore pressure is lost after approximately 0.5 diameters of movement, when a gap at the rear of the pipe causes pore pressures at the PPT location to become hydrostatic. The outcome - which is initially counter-intuitive - arises as more softening during pipe laying resulted in more net hardening after consolidation.

\section{Comparison with theoretical solutions for unconsolidated, undrained lateral breakout capacity}

The effect of pipe weight on the lateral breakout resistance for cases without post-lay consolidation is assessed through failure envelopes defining the combination of vertical and lateral loads in Figure 9. The unconsolidated undrained lateral breakout capacity, indicated by the individual data markers, is defined as the maximum resistance recorded during the lateral displacement of the pipe, and occurred after $x \sim 0.3 D$. Unconsolidated undrained failure envelopes in $V / D s_{u 0}-H / D s_{u 0}$ and $H / V-V / V_{u l t, U U}$ load spaces are shown on Figure 9(a) and Figure 9(b), respectively. These are based on the upper bound plasticity solution by Randolph and White (2008) for weightless soil, and numerical limit analysis by Martin and White (2012) for weighty soil. In both cases the pipe is assumed to be fully rough, wished-in-place and at an embedment of $w / D=0.5$ in a soil with strength proportional to depth. Both solutions underestimate the unconsolidated undrained lateral breakout capacity observed in the present set of centrifuge test results, which is attributed to the neglect of heave and soil berms as earlier 
demonstrated in Figure 3(b), noting that this penetration resistance would determine the size of

the failure envelope in the lateral load dimension.

The formation of soil heave beside the pipe during penetration is shown in Figure $\mathbf{1 0}$ through a sequence of underwater photographs taken during a pipe test. This heave results in an additional embedment, and provides additional resistance during lateral breakout as the pipe mobilises a greater volume of soil. The effect of the heave can be estimated by considering the volume of the soil displaced by the pipe during penetration. Dingle et al. (2008), through observations of the changes in soil surface profiles during pipe penetration using image analyses, estimated the effective increase in embedment, $\Delta w_{\text {heave }}$ as:

$$
\frac{\Delta w_{\text {heave }}}{D}=\frac{1}{8} \frac{D}{\left(0.8 D^{\prime}\right)}\left[\sin ^{-1}\left(\frac{D^{\prime}}{D}\right)-\frac{D^{\prime}}{D} \sqrt{1-\left(\frac{D^{\prime}}{D}\right)^{2}}\right]
$$

353 where $D^{\prime}=2 D\left[(w / D)-(w / D)^{2}\right]^{0.5}$. An effective embedment of $\sim 0.7 D$ for a pipe penetrated to $w=$ $3540.5 D$ is derived through Equation 12. The unconsolidated undrained failure envelope 355 corresponding to this effective embedment using the limit analysis solution by Martin and White 356 (2012) predicts well the lateral breakout capacity observed in the present set of centrifuge test 357 results shown in Figure 9.

Comparison with theoretical solutions for the consolidated, undrained lateral breakout capacity

359 The effect of pipe weight on the lateral breakout resistance for cases with post-lay consolidation 360 is assessed through failure envelopes in Figure 11.

361 The consolidated undrained lateral breakout capacity, indicated by individual data markers, is 362 defined as the peak resistance recorded during the immediate lateral displacement of the pipe, and 363 occurred during $x \sim 0.01 D$, which is a smaller displacement than for the unconsolidated cases. 
364 The consolidated undrained failure envelope is derived by scaling the unconsolidated undrained 365 envelope as a function of the increase in the undrained shear strength due to consolidation, $\Delta s_{u}$ 366 using an approach set out by Gourvenec et al. (2014) for shallow foundations. The mobilised soil 367 below the pipe is lumped as a single element for which the operative increment in consolidation 368 stress due to the preload can be estimated for initially normally consolidated conditions as:

$$
\Delta \sigma^{\prime}{ }_{c}=f_{\sigma}\left(\frac{N}{D}\right)
$$

369 where $N$ is the enhanced normal force that takes into account the wedging effect around the pipe 370 as defined by Equation 8 (Chatterjee et al. (2014)), whilst the factor $f_{\sigma}$ takes into account the 371 non-uniform distribution of the stress in the affected zone of soil. The resulting increase in 372 strength of the soil affected by consolidation is then calculated as:

$$
\Delta s_{u}=f_{s u} \Delta \sigma_{c}^{\prime}\left(\frac{s_{u}}{\sigma^{\prime}{ }_{v}}\right)_{N C}
$$

373 where the shear strength factor $f_{s u}$ scales the gain in strength of the 'lumped' soil to that mobilised 374 during subsequent failure, and $\left(s_{u} / \sigma_{v}^{\prime}\right)_{N C}$ is the normally consolidated strength ratio of the soil, 375 equivalent to 0.15 in the present test conditions.

376 The consolidated undrained vertical and lateral breakout capacities are assumed to scale with the 377 increase in the undrained shear strength in the form:

$$
\begin{aligned}
& \frac{V_{u l t, C U}}{V_{u l t, U U}}=1+\frac{\Delta s_{u}}{s_{u 0}}=1+f_{s u(V)} f_{\sigma}\left(\frac{s_{u}}{\sigma_{v}^{\prime}}\right)_{N C}\left(\frac{V}{D s_{u 0}}\right)_{U U} \\
& \frac{H_{u l t, C U}}{H_{u l t, U U}}=1+\frac{\Delta s_{u}}{s_{u 0}}=1+f_{s u(H)} f_{\sigma}\left(\frac{s_{u}}{\sigma_{v}^{\prime}}\right)_{N C}\left(\frac{V}{D s_{u 0}}\right)_{U U}
\end{aligned}
$$


where $\left(V / D s_{u 0}\right)_{U U}$ is the normalised unconsolidated undrained vertical pipe resistance mobilised at 379 the effective embedment. Separate scaling factors, $f_{\sigma}$ and $f_{s u}$ in Equations 15 - 16 allow the 380 response in the overconsolidated conditions to be captured, but in the present normally 381 consolidated conditions, there is effectively a single scaling parameter, $f_{\sigma} f_{s u}$ for a particular load 382 path. The increase in the vertical and lateral breakout capacities through consolidation as 383 observed in the present set of centrifuge test results is predicted well through Equations 15 - 16 384 using the scaling parameters $f_{\sigma} f_{s u(V)}=0.439$ derived in FEA studies carried out by Chatterjee et 385 al. (2014) for pipe, and $f_{\sigma} f_{s u(H)}=0.919$ derived by Feng and Gourvenec (2015) as shown in 386 Figure 11. The results demonstrate that the expansion of the failure envelopes through 387 consolidation is captured well by the theoretical framework outlined by Gourvenec et al. (2014), 388 where the increase in operative soil strength is linked to the pipe weight. The observed increase in 389 lateral breakout capacity, $H_{u l t}$, due to consolidation is higher than the predicted gain in vertical 390 pipe capacity, $V_{u l t}$, consistent with analysis of mudmat foundations (Feng and Gourvenec (2015)). 391 For the load levels used in the model test cases, the theoretical envelope and the experimental 392 results show gains in lateral breakout capacity of 20\% - 50\% (Figure 11).

\section{$393 \quad$ Pipe trajectory}

394 The effect of post-lay consolidation and installation or pipe 'laying' method on the pipe trajectory 395 during subsequent axial and lateral loading is summarised in Figure 12. The figure plots the 396 normalised pipe embedment at the invert level, $w / D$ against the normalised axial displacement, $397 y / D$ and normalised lateral displacement, $x / D$ for tests with $V_{o p} / V_{\max }=0.25$ (R4 series). Overall, 398 the trajectory is approximately the same with the pipe moving upwards as expected for the pipe 399 weight relative to the vertical bearing capacity, at a slope of $\sim 1^{\circ}$ and $\sim 10^{\circ}$ during axial and 400 lateral displacements, respectively. When the pipe is loaded axially or laterally immediately after 
the installation, larger upward displacements were recorded than during the movement of pipe after a period of post-lay consolidation.

The effect of pipe weight on the pipe trajectory during lateral loading is shown in Figure 13. The present centrifuge response is compared against LDFE analysis results reported in Wang et al. (2010), where the general behaviour between two set of results is similar with lighter pipes $\left(V_{o p}<\right.$ $\left.0.5 V_{\max }\right)$ rising from breakout embedment during lateral displacement, and heavier pipes moving downward penetrating deeper into the soil with increasing lateral displacement, $x / D$.

The direction of pipe displacement during lateral breakout at failure, $\delta w / \delta x$, for varying $V_{o p} / V_{\max }$ can be directly assessed by assuming an associated flow rule (or normality), where $\delta w / \delta u$ at failure can be assumed normal to the failure envelope defined in the $V-H$ load space. Recorded $\delta w / \delta x$ for a given $V_{o p} / V_{\max }$ obtained in the centrifuge tests are compared against existing solutions in Figure 14(a) and Figure 14(b) for cases without and with post-lay consolidation.

In general, $\delta w / \delta x$ observed in the centrifuge tests for $V_{o p}<0.5 \cdot V_{\max }$ on pipe with and without post-lay consolidation agrees closely with existing solutions based on large-deformation FEA estimates (Wang et al. (2010)), and based on limit analysis after accounting for the effective embedment as discussed above (Martin and White (2012)). However, both solutions slightly over predict $\delta w / \delta x$ for $V_{o p}>0.5 \cdot V_{\max }$.

\section{Concluding remarks}

This paper has presented results of a centrifuge test programme that investigated the influence of installation or laying method, and post-lay consolidation on the axial and lateral breakout response of a pipeline section on a normally consolidated soil.

Different initial conditions involving varying levels of generation and dissipation of excess pore pressure during pipe installation, and operative vertical loads (representing a range of pipe 
424 weight) were explored. Axial and lateral breakout response of the pipe was assessed under undrained loading conditions immediately after installation, or after a period of consolidation to allow essentially full dissipation of the excess pore pressures developed during installation.

The results showed a strong installation effect. This effect results from post-laying consolidation, and is enhanced if the lay process involves remoulding. Four key conclusions emerge following the observations made:

- After pipeline installation, the strength of the surrounding soil can be significantly enhanced due to consolidation under the pipe self-weight.

- Cyclic pipe movements or oscillations during installation create additional excess pore pressure in the soil surround the pipeline. Although this remoulding weakens the soil in the short term, the subsequent strength gain during consolidation is greater than following monotonic installation.

- The axial and lateral breakout resistance is significantly enhanced by these changes in strength - by $20 \%-50 \%$ for the cases in this study. The relevant operative strength should be used with existing solutions to estimate breakout resistance. A theoretical framework and numerically derived scaling factors were presented for the pipeline conditions considered in this study.

- The penetration of the pipe results in additional embedment due to the development of soil heave next to the embedded pipe. This additional effective embedment results in additional breakout resistance, and existing numerical and analytical solutions based on wished-in-place (no heave) conditions should be modified using the effective embedment. When the solutions are applied in this way, in combination with the in situ soil strength, the response is predicted well. 
447 These results illustrate how the installation process and post-installation consolidation effects

7

9 10
448 combine to alter the soil strength around a seabed pipeline, and show how existing prediction 449 methods can capture these effects.

\section{Acknowledgements}

451 The work described here forms part of the activities of the Centre for Offshore Foundation 452 Systems, currently supported as a node of the Australian Research Council Centre of Excellence 453 for Geotechnical Science and Engineering. This support is gratefully acknowledged. The 454 technical support provided by beam centrifuge technician, Mr. Manuel Palacios is also gratefully 455 acknowledged. The third author acknowledges the support of the Shell EMI Chair in Offshore 456 Engineering, at UWA. 


\section{Notations}

459 The following symbols were used in the paper.

D pipe diameter

$L \quad$ pipe length

$\left(s_{u} / \sigma_{v}^{\prime}\right)_{N C} \quad$ normally consolidated strength ratio

$\left(V / D s_{u 0}\right)_{U U} \quad$ normalised unconsolidated undrained vertical pipe resistance mobilised at the effective embedment

$A_{d} / A_{P} \quad$ ratio of the shaft to the projected area of the ball penetrometer

$c_{v} \quad$ vertical coefficient of consolidation

$D^{\prime} \quad$ effective contact width of the pipe

$f_{b}$

soil buoyance enhancement factor

$F_{\text {buoy }} \quad$ soil buoyancy force on the ball penetrometer

$f_{\sigma} \quad$ stress factor

$f_{s u} \quad$ strength factor

$H / D s_{u 0} \quad$ normalised lateral resistance

$H / \mathrm{V} \quad$ lateral friction factor

$H_{a x} \quad$ axial horizontal load

$H_{a x} / D s_{u 0} \quad$ normalised axial breakout resistance

$H_{a x} N \quad$ axial friction factor

$k$

undrained shear strength gradient

$m \quad$ constant

$N^{\prime}$

effective normal force around the pipe-soil contact

$N_{95} \quad$ number of cycles required to achieve $95 \%$ of fully remoulded strength from the intact strength

$N_{b} \quad$ self-weight factor

$N_{\text {ball }} \quad$ ball penetrometer factor

$N_{c} \quad$ soil bearing factor reflecting the soil resistance component

$p \quad$ pipe-soil contact perimeter

$q_{\text {ball }} \quad$ penetration resistance measured by the ball penetrometer

$q_{m} \quad$ net penetration resistance of the ball penetrometer 
undrained shear strength

cyclic/remoulded undrained shear strength

intact, in situ, undrained shear strength

mudline undrained shear strength

non-dimensional time factor

time

time factor when $50 \%$ of the increase in total contact enhancement factor, $\zeta$ has occurred

pore pressure

hydrostatic pressure

pore pressure at the pipe invert (averaged)

pore pressure at the side pore pressure transducers (averaged)

pipe vertical bearing pressure per unit length

normalised vertical penetration resistance

vertical load at a penetration of $w / D=0.5$

operative vertical load

unloading ratio

consolidated undrained ultimate vertical load capacity

unconsolidated undrained ultimate vertical load capacity

pipe penetration at the invert level

lateral displacement

normalised lateral displacement

axial displacement

normalised axial displacement

depth

net area ratio of the load cell core to the shaft area

pipe-soil friction angle

final remoulded strength of the soil

increase in the undrained shear strength due to consolidation

excess pore pressure around the pipe 


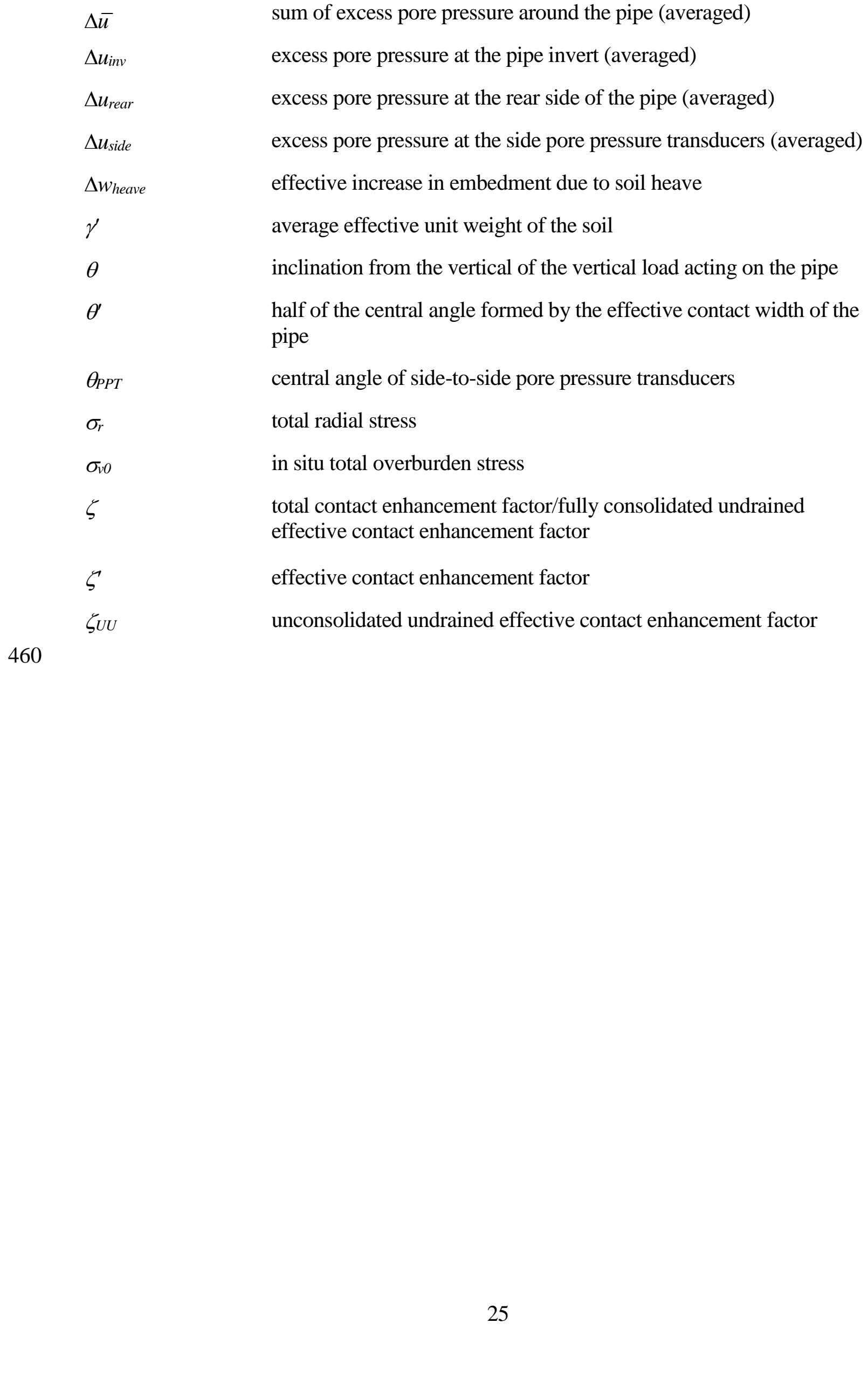




\section{References}

Aubeny, C. P., Shi, H. \& Murff, J. D. (2005) Collapse Loads for a Cylinder Embedded in Trench in Cohesive Soil. International Journal of Geomechanics 5(4):320-325.

Bruton, D., White, D., Cheuk, C., Bolton, M. \& Carr, M. (2006) Pipe/Soil Interaction Behavior During Lateral Buckling, Including Large-Amplitude Cyclic Displacement Tests by the Safebuck JIP. In Offshore Technology Conference.) Offshore Technology Conference, Houston.

Bruton, D. a. S., White, D. J., Carr, M., Cheuk, J. C. Y. \& Kong, H. (2008) Pipe-Soil Interaction During Lateral Buckling and Pipeline Walking — The SAFEBUCK JIP. Proc. Offshore Technol. Conf., Houston, TX, Paper OTC19589.

Cardoso, C. O. \& Silveira, R. (2010) Pipe-Soil Interaction Behavior for Pipelines Under Large Displacements on Clay Soils - A Model for Lateral Residual Friction Factor In Proceedings of Offshore Technology Conference. Offshore Technology Conference.

Chatterjee, S., Gourvenec, S. \& White, D. J. (2014) Assessment of the consolidated breakout response of partially embedded subsea pipelines. Géotechnique 64(5):391-399.

Chatterjee, S., Randolph, M. F. \& White, D. J. (2012a) The effects of penetration rate and strain softening on the vertical penetration resistance of seabed pipelines. Géotechnique 62(7):573-582.

Chatterjee, S., White, D. \& Randolph, M. (2012b) Numerical simulations of pipe-soil interaction during large lateral movements on clay. Géotechnique 62(8):693-705. 
Chatterjee, S., White, D. J. \& Randolph, M. F. (2013) Coupled consolidation analysis of pipesoil interactions. Canadian Geotechnical Journal 50(6):609-619.

Chatterjee, S., Yan, Y., Randolph, M. \& White, D. (2012c) Elastoplastic consolidation beneath shallowly embedded offshore pipelines. Géotechnique Letters 2(2):73-79.

Cheuk, C. Y., White, D. J. \& Bolton, M. D. (2007) Large-scale modelling of soil-pipe interaction during large amplitude cyclic movements of partially embedded pipelines. Canadian Geotechnical Journal 44(8):977-996.

Chung, S. F. \& Randolph, M. (2004) Penetration resistance in soft clay for different shaped penetrometers. In Proceedings of the 2nd International Conference on Site Characterization.) Millpress Science, vol. 1, pp. 671-677.

Cocjin, M., Gourvenec, S., White, D. \& Randolph, M. (2014) Tolerably mobile subsea foundations - observations of performance. Géotechnique 64(11):895-909.

Colreavy, C., O'loughlin, C. D. \& Randolph, M. (2016) Experience with a dual pore pressure element piezoball. International Journal of Physical Modelling in Geotechnics 16(3):101118.

De Catania, S., Breen, J., Gaudin, C. \& White, D. J. (2010) Development of a multiple-axis actuator control system. In Physical Modelling in Geotechnics, Two Volume Set.) CRC Press, pp. 325-330.

Dingle, H. R. C., White, D. J. \& Gaudin, C. (2008) Mechanisms of pipe embedment and lateral breakout on soft clay. Canadian Geotechnical Journal 45(5):636-652.

Einav, I. \& Randolph, M. F. (2005) Combining upper bound and strain path methods for evaluating penetration resistance. International Journal for Numerical Methods in Engineering 63(14):1991-2016. 
Feng, X. \& Gourvenec, S. (2015) Consolidated undrained load-carrying capacity of subsea mudmats under combined loading in six degrees of freedom. Géotechnique 65(7):563575.

Gaudin, C., White, D. J., Boylan, N., Breen, J., Brown, T., De Catania, S. \& Hortin, P. (2009) A wireless high-speed data acquisition system for geotechnical centrifuge model testing. Measurement Science and Technology 20(9):095709.

Gourvenec, S., Acosta-Martinez, H. \& Randolph, M. (2009) Experimental study of uplift resistance of shallow skirted foundations in clay under transient and sustained concentric loading. Géotechnique 59(6):525-537.

Gourvenec, S. M., Vulpe, C. \& Murthy, T. G. (2014) A method for predicting the consolidated undrained bearing capacity of shallow foundations. Géotechnique 64(3):215-225.

Hill, A. J., White, D. J., Bruton, D. a. S., Langford, T., Meyer, V., Jewell, R. \& Ballard, J. C. (2012) A new framework for axial pipe-soil resistance, illustrated by a range of marine clay satasets. In 7th Int. Conf. on Offshore Site Investigation and Geotechnics.) Society of Underwater Technology, London.

Krost, K., Gourvenec, S. M. \& White, D. J. (2011) Consolidation around partially embedded seabed pipelines. Géotechnique 61(2):167-173.

Low, H., Randolph, M. \& Kelleher, P. (2007) Comparison of pore pressure generation and dissipation rates from cone and ball penetrometers. In Offshore Site Investigation Confronting New Challenges and Sharing Knowledge.) Society for Underwater Technology, vol. n/a, pp. 547-556.

Low, H. E., Lunne, T., Andersen, K. H., Sjursen, M. A., Li, X. \& Randolph, M. F. (2010) Estimation of intact and remoulded undrained shear strengths from penetration tests in soft clays. Géotechnique 60(11):843-859. 
Martin, C. M. \& Randolph, M. F. (2006) Upper-bound analysis of lateral pile capacity in cohesive soil. Géotechnique 56(2):141-145.

Martin, C. M. \& White, D. J. (2012) Limit analysis of the undrained bearing capacity of offshore pipelines. Géotechnique 62(9):847-863.

Merifield, R., White, D. \& Randolph, M. (2009) Effect of Surface Heave on Response of Partially Embedded Pipelines on Clay. Journal of Geotechnical and Geoenvironmental Engineering 135(6):819-829.

Merifield, R., White, D. J. \& Randolph, M. F. (2008) The ultimate undrained resistance of partially embedded pipelines. Géotechnique 58(6):461-470.

Murff, J. D., Wagner, D. A. \& Randolph, M. F. (1989) Pipe penetration in cohesive soil. Géotechnique 39(2):213-229.

Randolph, M. \& Hope, S. (2004) Effect of cone velocity on cone resistance and excess pore pressures. In Proceedings of the IS Osaka - Engineering Practice and Performance of Soft Deposits.) Yodogawa Kogisha Co. Ltd, pp. 147-152.

Randolph, M. F. \& Houlsby, G. T. (1984) The limiting pressure on a circular pile loaded laterally in cohesive soil. Géotechnique 34(4):613-623.

Randolph, M. F., Jewell, R. J., Stone, K. J. \& Brown, T. A. (1991) Establishing a new centrifuge facility. In international conference on centrifuge modelling, Centrifuge '91. (Ko, H.-Y., andMclean, F. G. (eds)) Balkema, Boulder pp. 3-9.

Randolph, M. F. \& White, D. J. (2008) Upper-bound yield envelopes for pipelines at shallow embedment in clay. Géotechnique 58(4):297-301.

Randolph, M. F., White, D. J. \& Yan, Y. (2012) Modelling the axial soil resistance on deep-water pipelines. Géotechnique 62(9):837-846. 
Sinclair, F., Carr, M., Bruton, D. \& Farrant, T. (2009) Deesign challenges and experience with controlled lateral buckle initiation methods In Proceedings of 28th International Conference on Ocean, Offshore and Arctic Engineering. ASME vol. 3, pp. 319-330.

Wang, D., White, D. J. \& Randolph, M. F. (2010) Large-deformation finite element analysis of pipe penetration and large-amplitude lateral displacement. Canadian Geotechnical Journal 47(8):842-856.

White, D. J. \& Randolph, M. F. (2007) Seabed characterisation and models for pipeline-soil interaction. International Journal of Offshore and Polar Engineering 7(3):193-204. 
Table 1 Pipe test s programme

\begin{tabular}{|c|c|c|c|c|c|c|}
\hline Test name & $\begin{array}{c}\text { Initial } \\
\text { penetration, } \\
w / D \\
\end{array}$ & $\begin{array}{c}\text { Recorded max. } \\
\text { penetration resistance, } \\
V_{\max }: \mathrm{kN} / \mathrm{m} \\
\end{array}$ & $\begin{array}{l}\text { Vertical load ratio, } \\
V_{o p} / V_{\max } \text { during post- } \\
\text { lay consolidation }\end{array}$ & $\begin{array}{c}\text { Vertical } \\
\text { installation }\end{array}$ & $\begin{array}{c}\text { Consolidation prior to } \\
\text { break-out }\end{array}$ & $\begin{array}{l}\text { Loading } \\
\text { conditions }\end{array}$ \\
\hline \multicolumn{7}{|l|}{$\begin{array}{l}\text { Axial } \\
\text { breakout }\end{array}$} \\
\hline R4UU_AX & \multirow{2}{*}{0.5} & 2.8 & 0.25 & \multirow{2}{*}{ Monotonic } & No & $\S$ \\
\hline R4CU_AX & & 2.4 & 0.25 & & Yes & $\dagger$ \\
\hline \multicolumn{7}{|l|}{$\begin{array}{l}\text { Lateral } \\
\text { breakout }\end{array}$} \\
\hline R4UU & \multirow{6}{*}{0.5} & 2.9 & 0.25 & \multirow{6}{*}{ Monotonic } & No & $\S$ \\
\hline R8UU & & 2.7 & 0.125 & & No & $\S$ \\
\hline $\mathrm{R} 1 \mathrm{CU}$ & & 2.7 & 1 & & Yes & $\dagger$ \\
\hline $\mathrm{R} 2 \mathrm{CU}$ & & 2.6 & 0.5 & & Yes & $\dagger$ \\
\hline $\mathrm{R} 4 \mathrm{CU}$ & & 2.6 & 0.25 & & Yes & $\dagger$ \\
\hline R8CU & & 2.9 & 0.125 & & Yes & $\dagger$ \\
\hline RemR4CU & & 1.9 & 0.25 & $\begin{array}{l}\text { Cyclic with } \\
\text { oscillations in } x \\
\text { direction }\end{array}$ & Yes & $\$$ \\
\hline \multicolumn{7}{|c|}{$\begin{array}{l}\text { Detailed test procedure } \\
\S \text { - Monotonic penetration to } w / D\left(V_{\max }\right) \rightarrow \text { Unload to } V_{o p} / V_{\max } \rightarrow \text { Breakout } \\
\dagger \text { - Monotonic penetration to } w / D\left(V_{\max }\right) \rightarrow \text { Unload to } V_{o p} / V_{\max } \rightarrow \text { Consolidate } \rightarrow \text { Breakout } \\
\$ \text { - Cyclic penetration to } w / D\left(V_{\max }\right) \rightarrow \text { Unload to } V_{o p} / V_{\max } \rightarrow \text { Consolidate } \rightarrow \text { Breakout } \\
\end{array}$} \\
\hline
\end{tabular}


1

2

3

4

5

6

7

8

9

10

11

12

13

14

15

16

17

18

19

20

21

22

23

24

25

26

27

28

29

30

31

32

33

34

35

36

37

38

39

40

41

42

43

44

45

46

47

48462

49

50

51

53

54

55

56

57

58

59

60

61

62

63

64

65

\section{$461 \quad$ Figures}
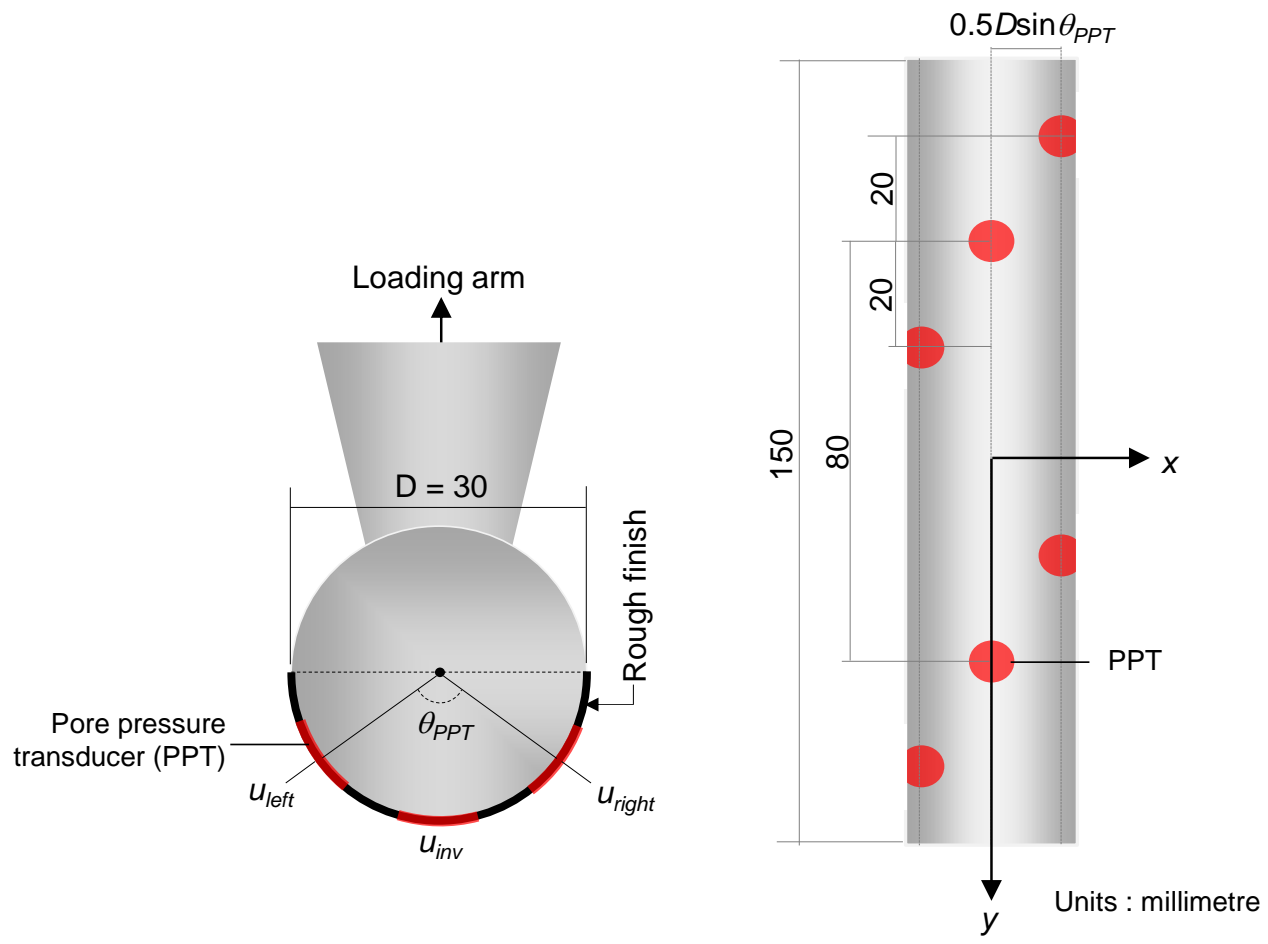

(a)

(b)

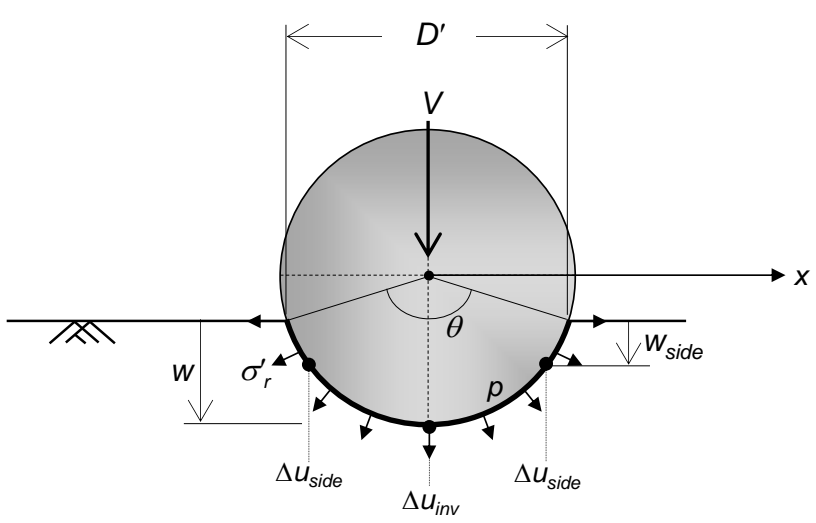

(c)

463 Figure 1 Schematic drawing of model pipe: in (a) transverse and (b) plan view; and (c)

464 idealisation of loads acting on the pipe 


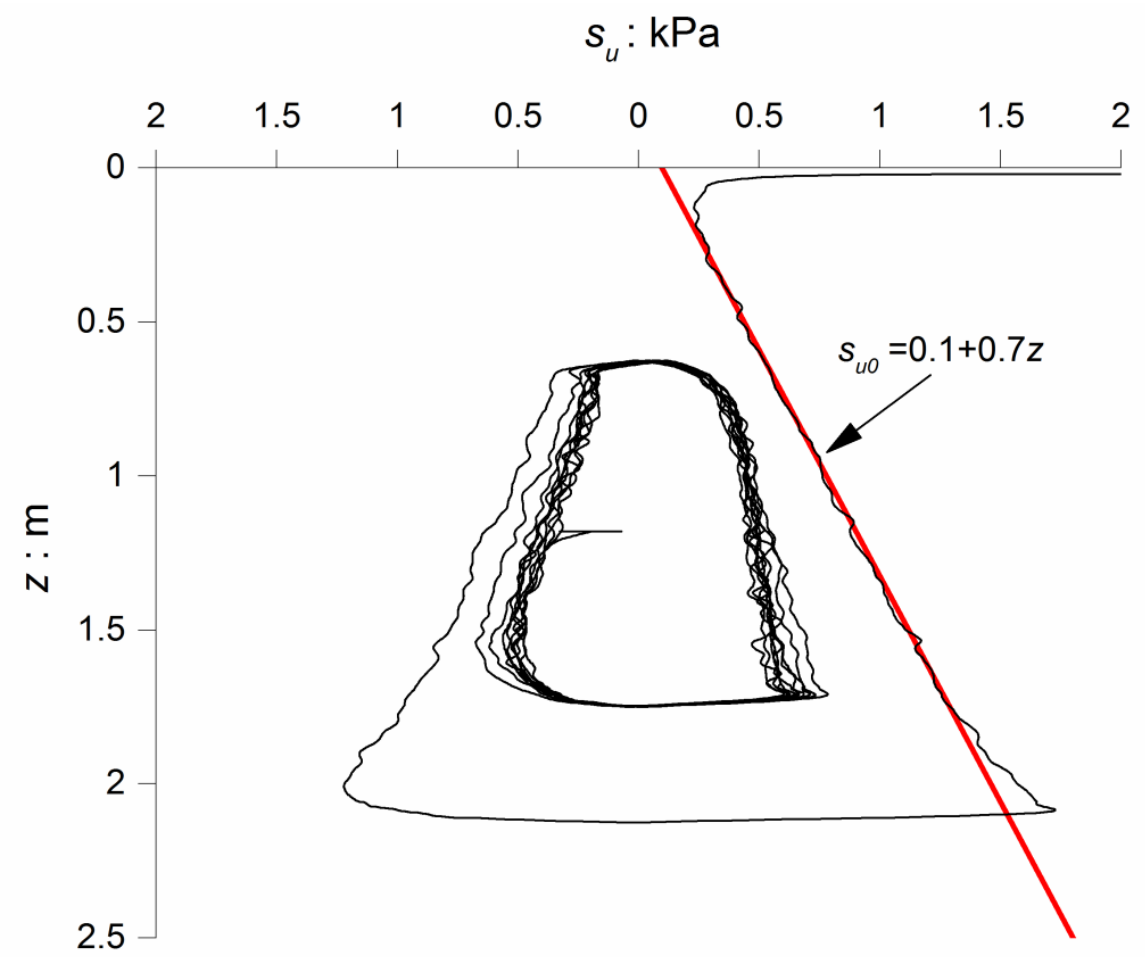

(a)

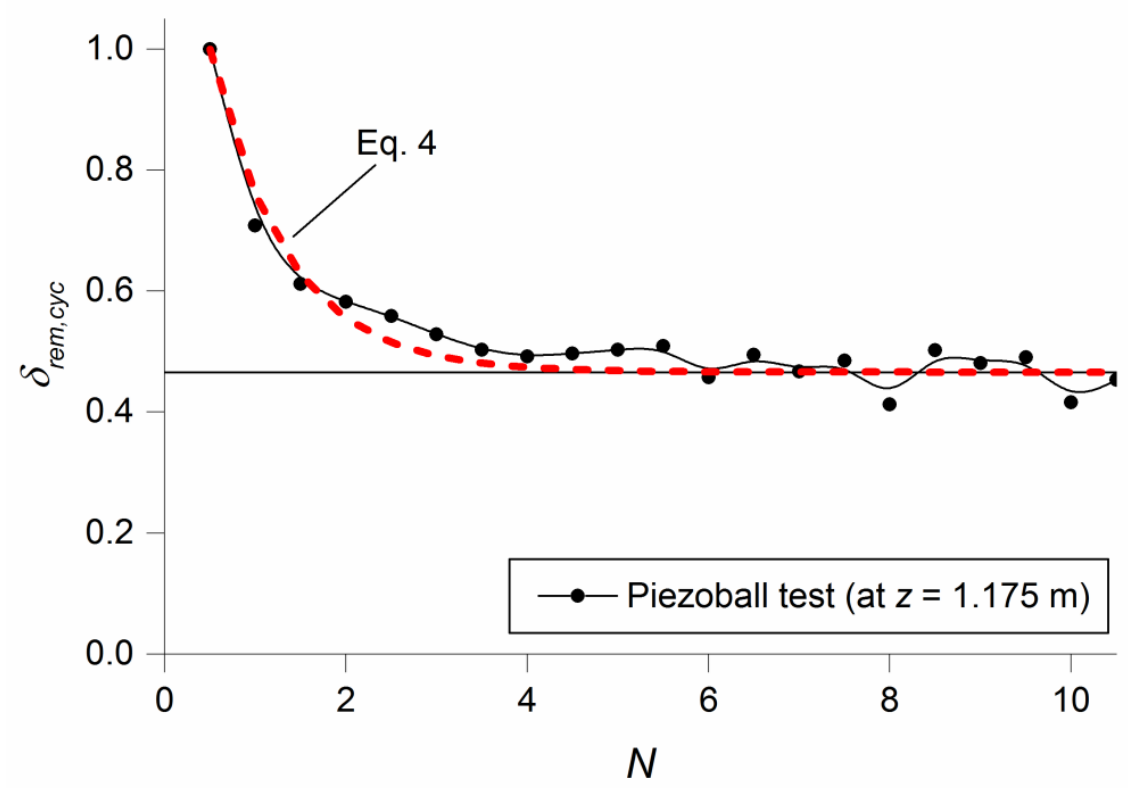

(b)

466 Figure 2 Characterisation of the soil model using a ball penetrometer showing: (a) undrained 467 shear strength, $s_{u}$ with depth, $z$ (prototype scale), and (b) degradation of soil strength during cyclic 468 penetrometer test plotted in terms of remoulded strength ratio, $\delta_{\text {rem,cyc }}=s_{u, c y d} s_{u 0}$ against cycle 469 number, $N$ 


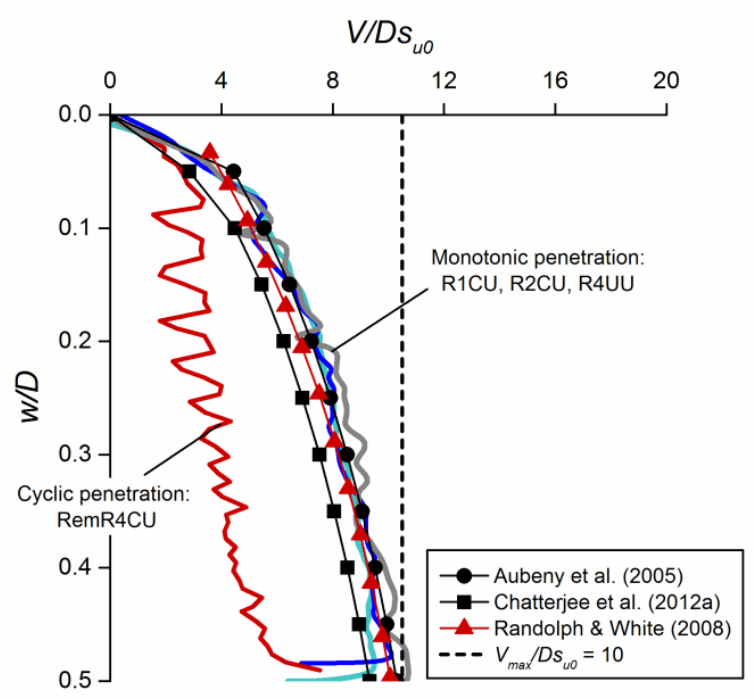

(b)

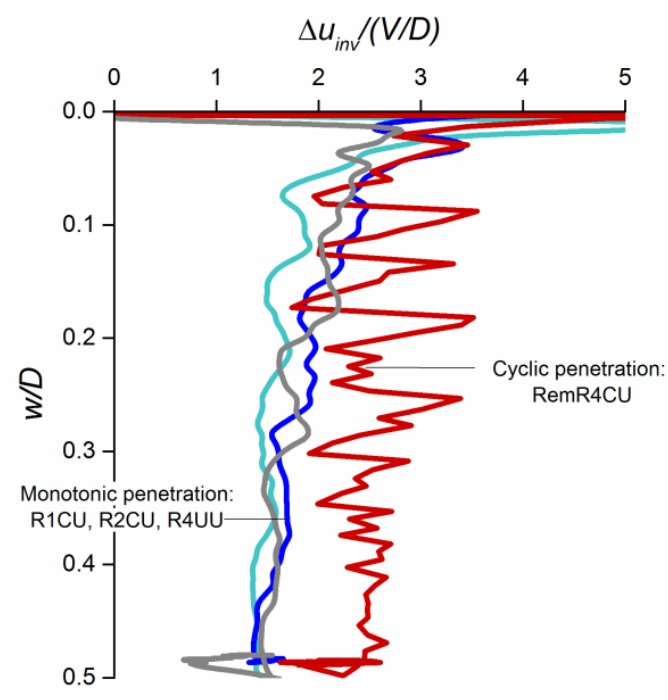

(c)

Figure 3 Undrained pipe penetration response showing: (a) buoyancy resistance, $N_{b} \gamma^{\prime} w$ and 472 vertical bearing pressure per unit length, $V / D$; (b) normalised vertical penetration resistance, $473 V / D s_{u 0}$; and (c) excess pore water pressure at the pipe invert normalised by vertical bearing 474 pressure per unit length, $\Delta u_{i n v} /(V / D)$, plotted against the normalised pipe embedment at the invert 475 level, $w / D$, during penetration (inset in (a): pipe displacement in lateral and vertical directions $476(x / D-w / D)$ during monotonic and cyclic penetration) 


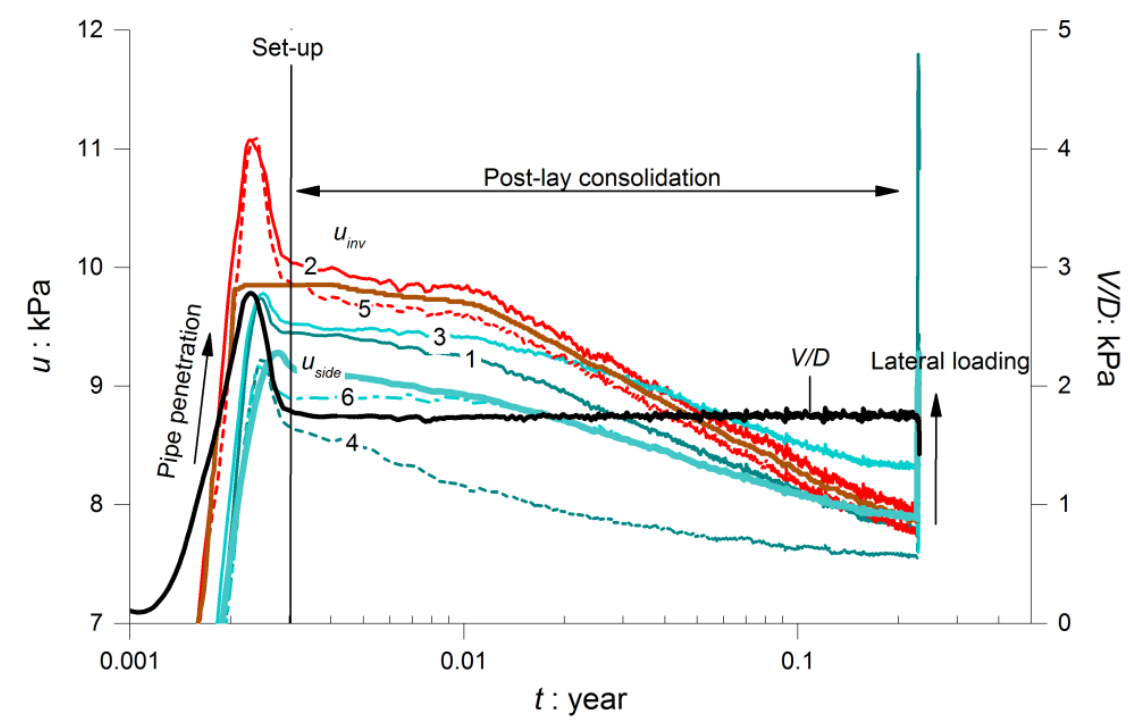

(a)

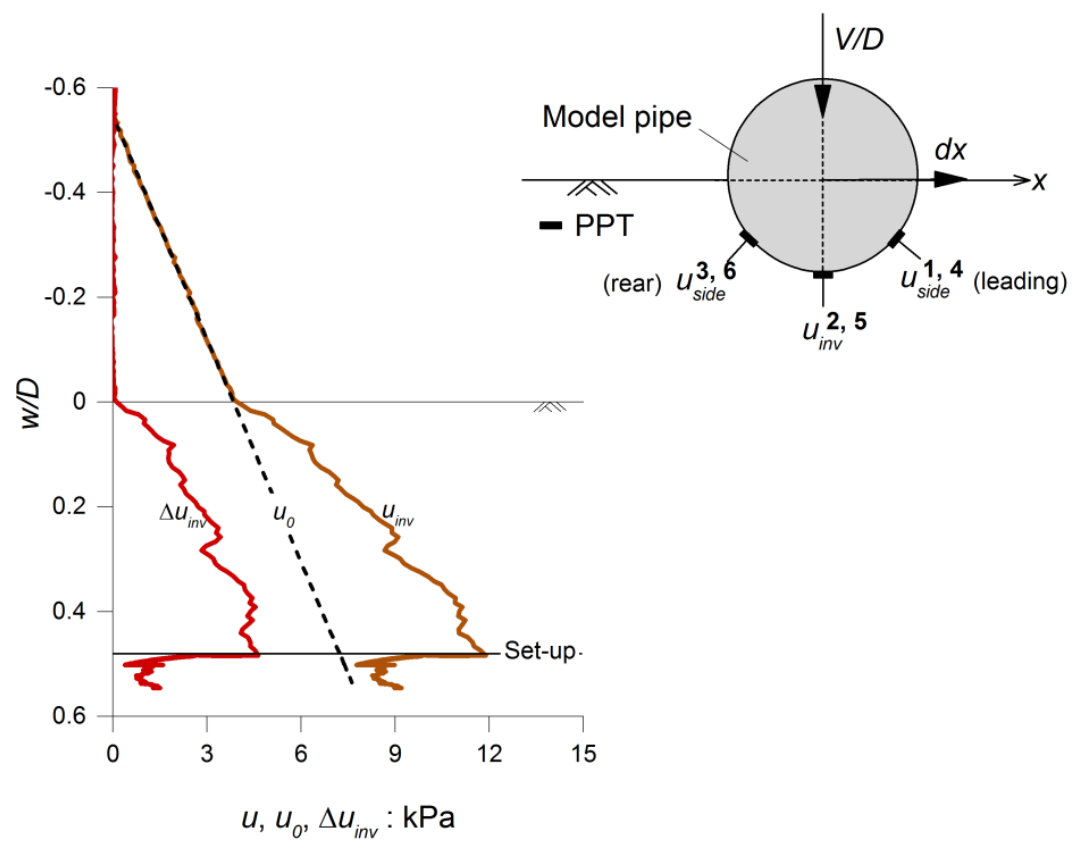

(b)

479 Figure 4 Variation in pore water pressure along the embedded pipe in test R2CU, showing: (a) 480 pore water pressure, $u$ measured at different pore pressure transducers (PPTs), and penetration 481 resistance $V / D$, during the whole test, plotted against time, $t$ in prototype scale; (b) hydrostatic 482 pore water pressure, $u_{0}$, and pipe invert record of pore water pressure, $u_{i n v}$, and excess pore water 483 pressure, $\Delta u_{i n v}$, plotted against normalised pipe embedment at the invert level, $w / D$ during 484 penetration 


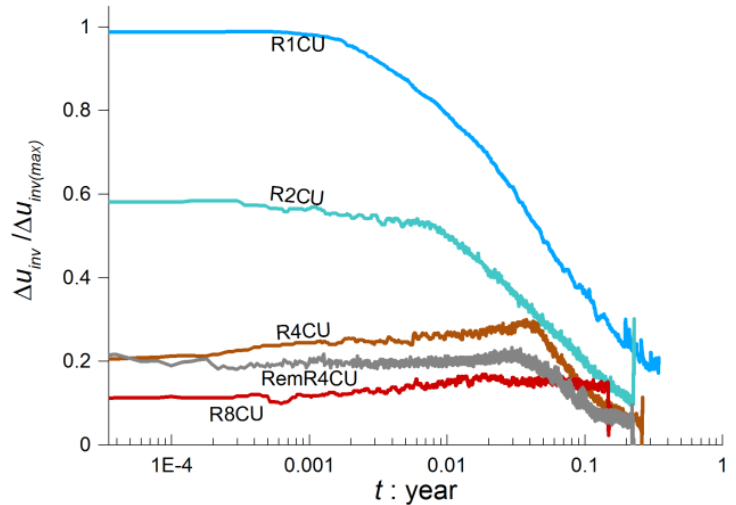

(a)

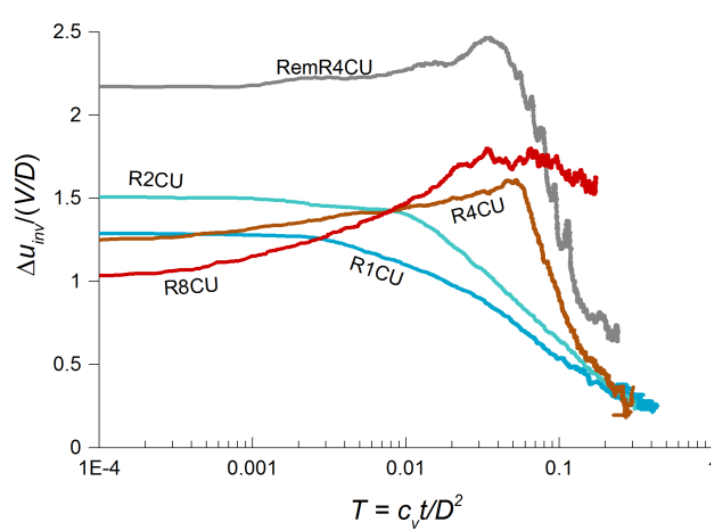

(b)

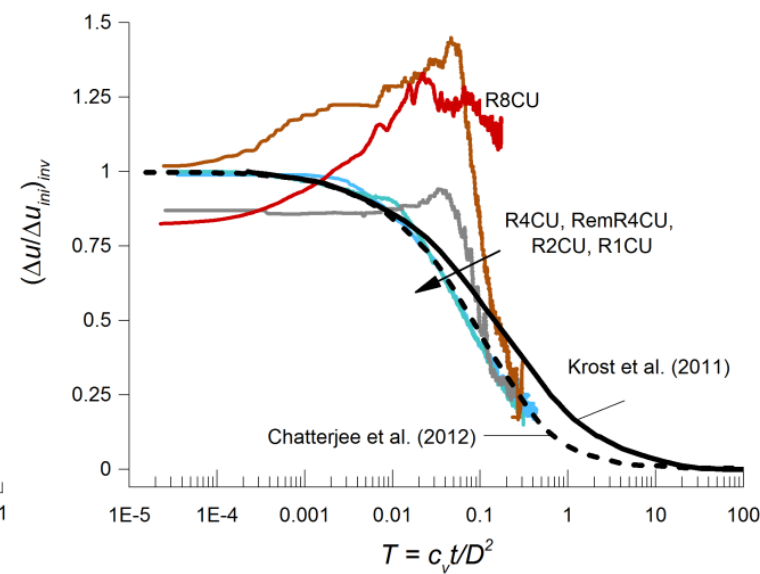

(c)

486 Figure 5 Dissipation-time histories of excess pore pressure at the pipe invert, $\Delta u_{\text {inv }}$ during

487 consolidation: (a) normalised by initial excess pore pressure at maximum vertical load, $\Delta u_{\text {inv }}(\max )$ 488 plotted against time, $t$ in prototype scale; (b) normalised by penetration resistance, $V / D$ plotted against time factor, $T=c_{v} t / D^{2}$ and (c) normalised by initial excess pore pressure under operative consolidation load, $\left(\Delta u_{i n i}\right)_{i n v}$ plotted against time factor, $T=c_{v} t / D^{2}$, where $t=0$ at the moment 491 when the reduction in vertical load is complete 


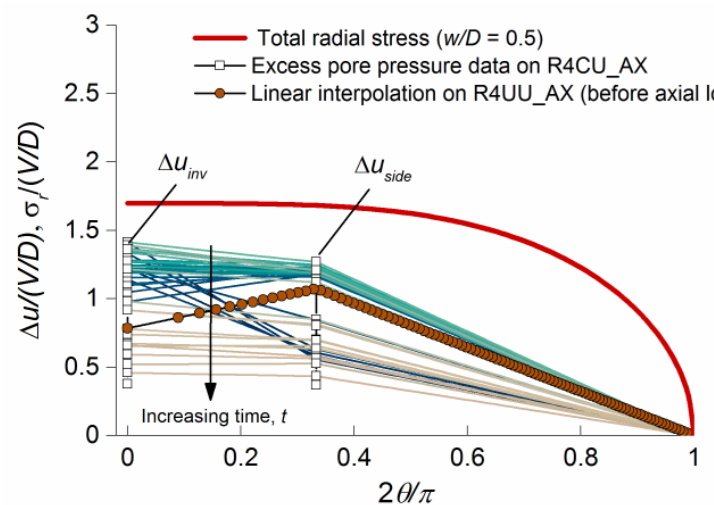

(a)

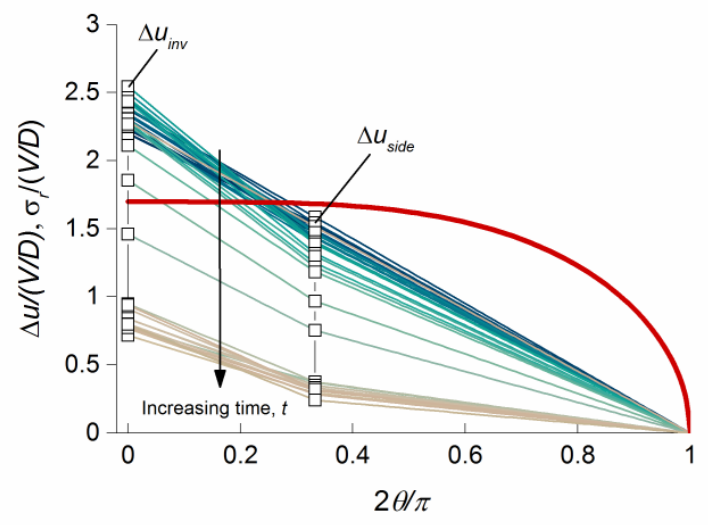

(b)

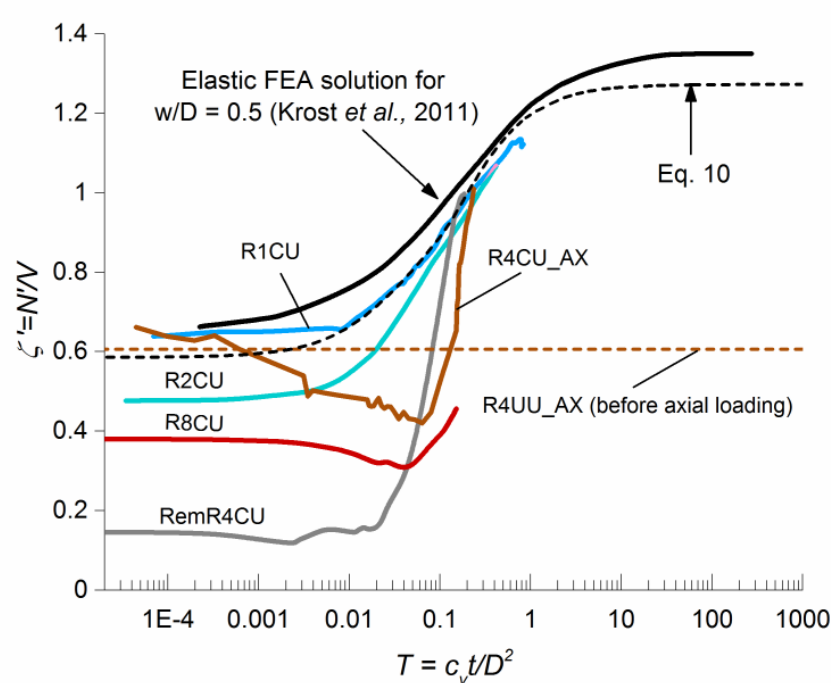

(c)

493 Figure 6 Effect of consolidation on pipe-soil contact stresses showing distribution of the total 494 radial stress, $\sigma_{r}$ and the interpolated excess pore pressure, $\Delta u$ normalised by the prescribed 495 vertical bearing pressure, V/D during tests (a) R4CU_AX, and R4UU_AX (before axial loading) 496 and (b) RemR4CU, and (c) increase in effective contact enhancement factor, $\zeta$ with time 497 expressed as time factor, $T=c_{v} t / D^{2}$ 


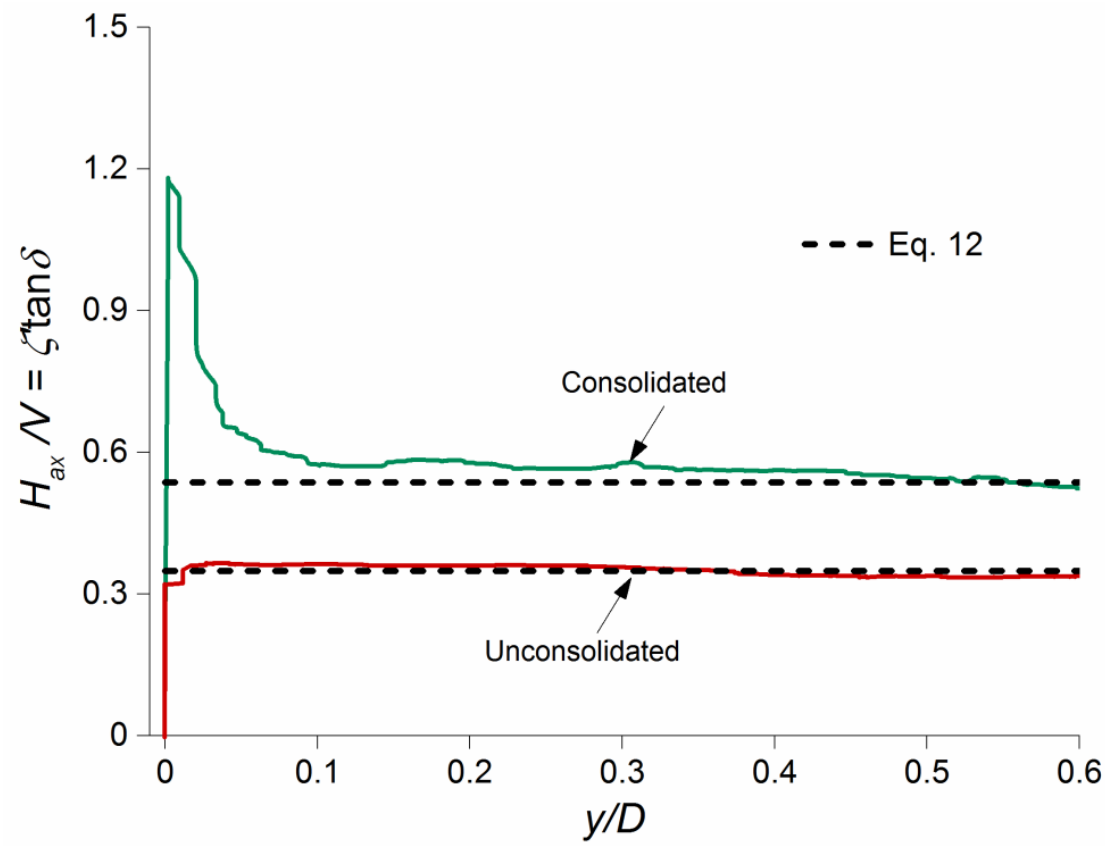

(a)

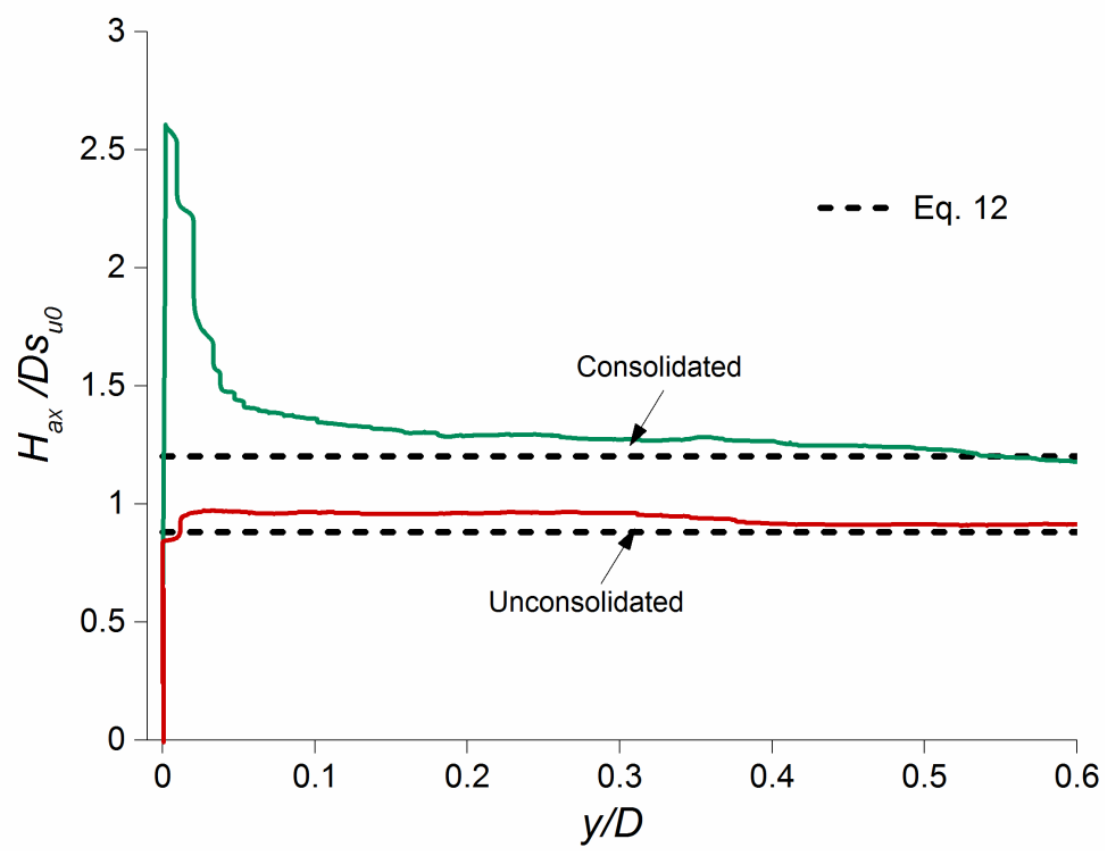

(b)

499 Figure 7 Effect of consolidation on axial pipe resistance showing: (a) axial friction factor, $H_{a \downarrow} \sqrt{ } V$

500 and (b) normalised axial breakout resistance, $H_{a \downarrow} / D s_{u}$ o, plotted against normalised axial 501 displacement, $y / D$ 


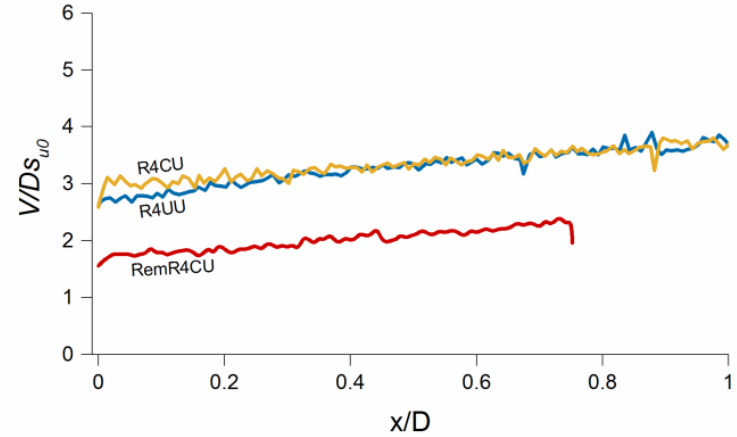

(c)

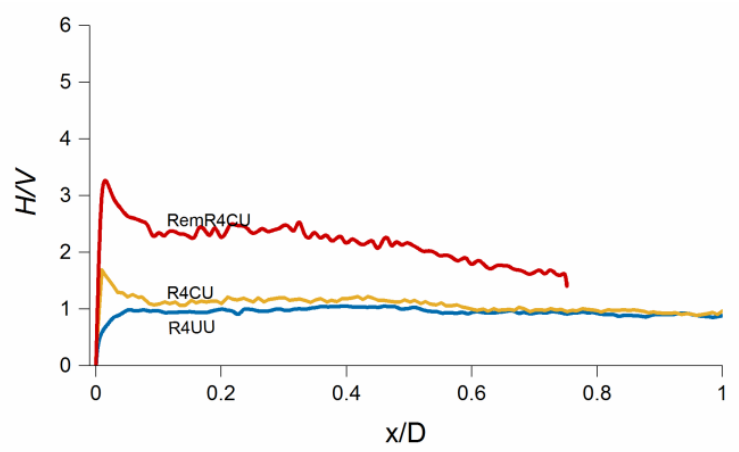

(b)

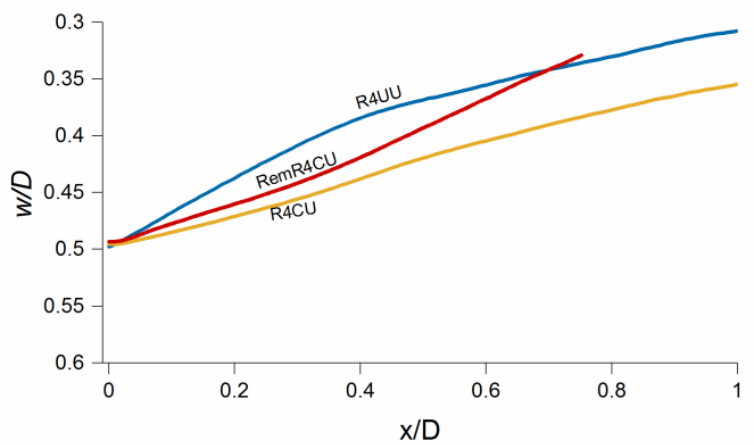

(d)

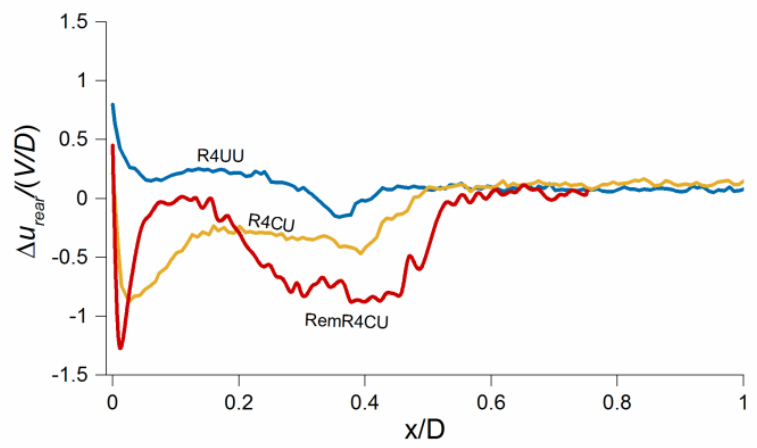

(e)

503 Figure 8 Effect of installation and post-lay consolidation on the lateral breakout resistance,

504 showing (a) lateral resistance normalised by the in situ, undrained shear strength at the level of 505 the pipe invert, $H / D s_{u 0}\left(s_{u 0}\right.$ not constant), (b) lateral friction factor, $H / V$, (c) normalised vertical 506 resistance, $V / D s_{u} 0$, (d) normalised pipe invert elevation, $w / D$, and (e) excess pore pressure at the 507 rear face of the pipe, $\Delta u_{\text {rear }}$ normalised by the vertical bearing pressure per unit length, $V / D$, 508 plotted against normalised lateral displacement, $x / D$ for tests with operative vertical load ratios, $509 V_{\text {op }} / V_{\max }=0.25(\mathrm{R} 4$ series $)$ 

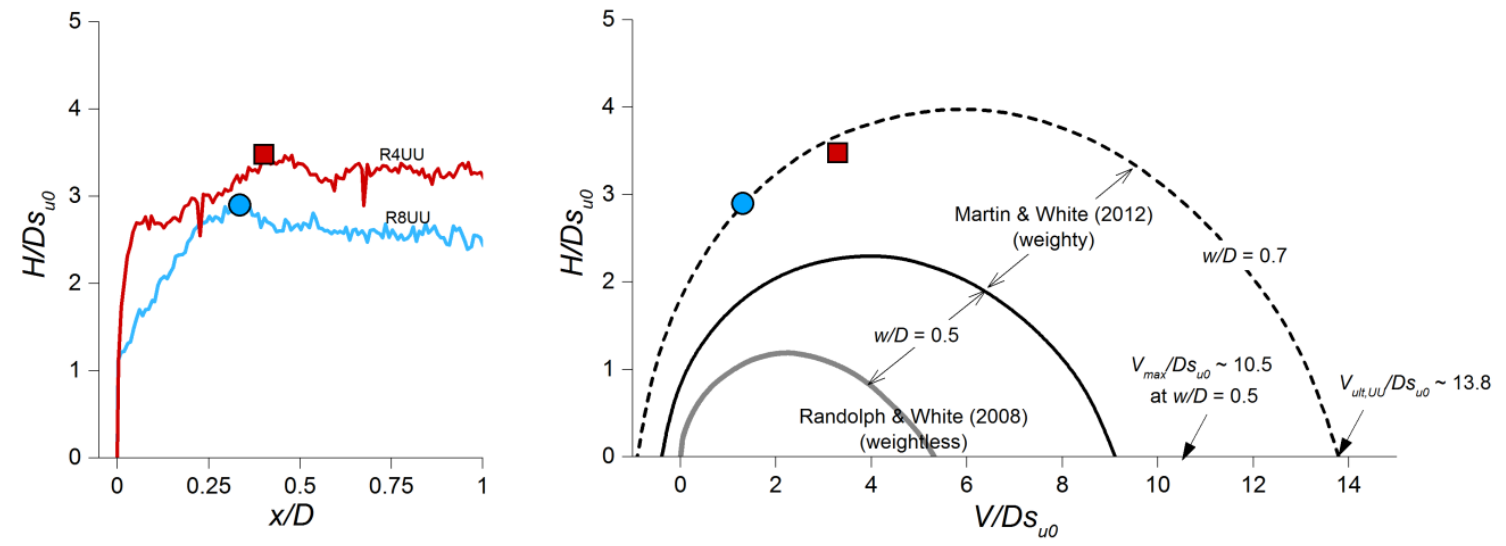

(a)
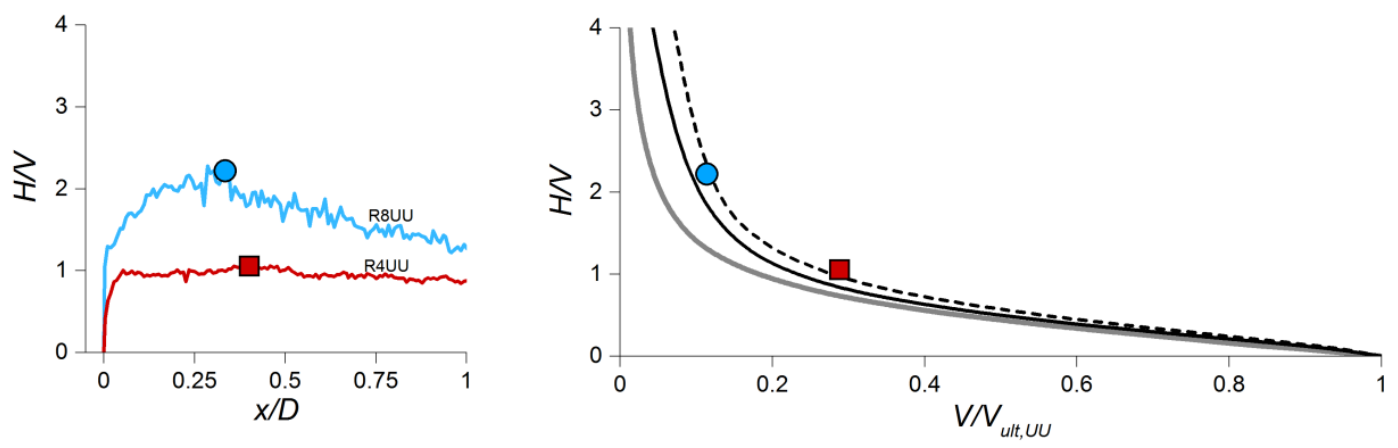

(b)

511 Figure 9 Unconsolidated lateral breakout responses, showing: (a) normalised lateral resistance,

$512 H / D s_{u 0}$, and (b) lateral friction factor, $H / V$ responses, relative to theoretical failure envelopes 


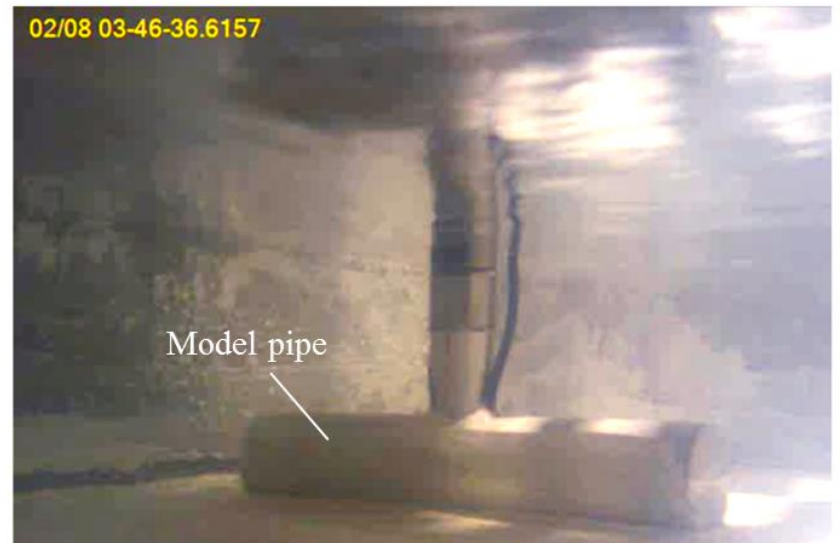

(a)

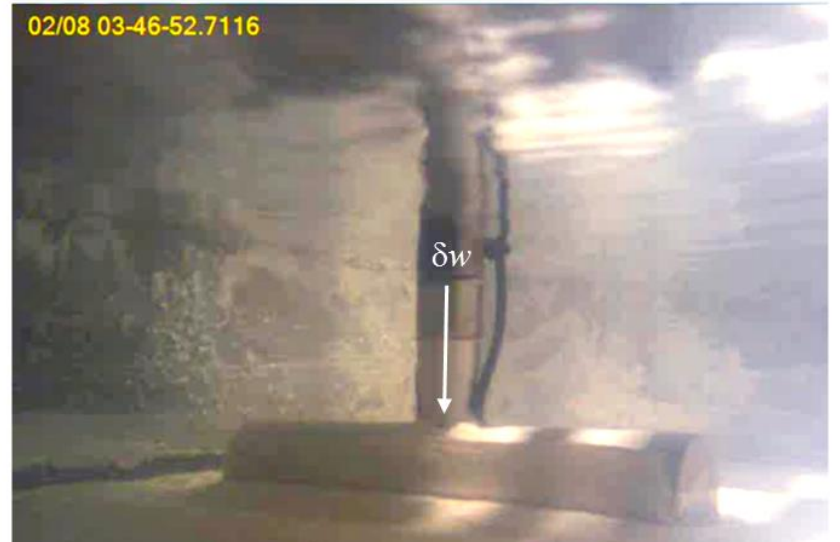

(b)

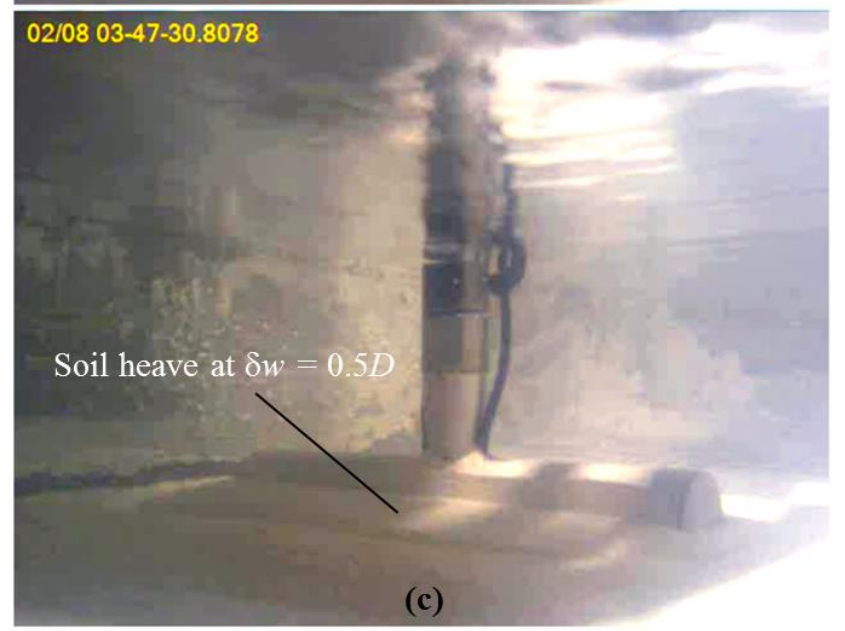

515 Figure 10 Development of soil heave during pipe penetration, shown by a sequence of test

516 photos in the following order: (a) before penetration, (b) during penetration, and (c) at maximum 517 penetration 

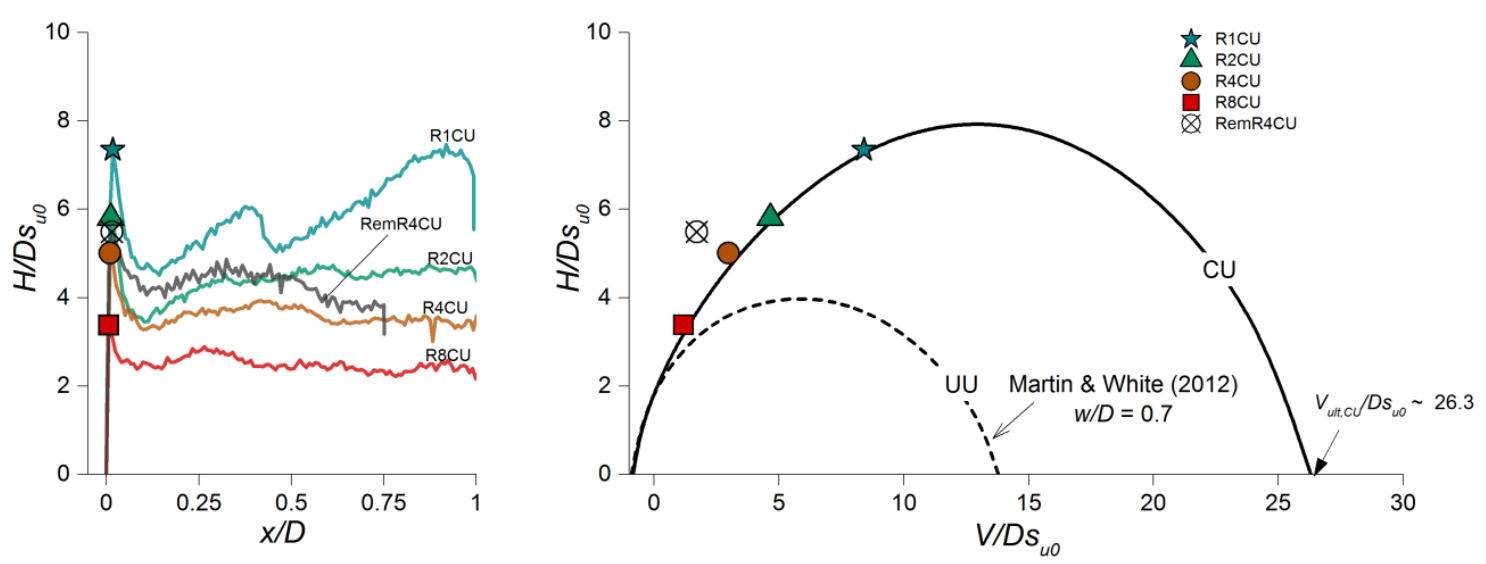

(a)

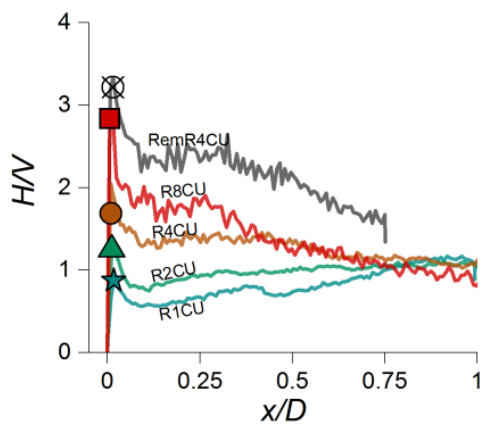

519 Figure 11 Consolidated lateral breakout responses, showing: (a) normalised lateral resistance, $520 H / D s_{u 0}$, and (b) lateral friction factor, $H / V$ responses, relative to theoretical failure envelopes 


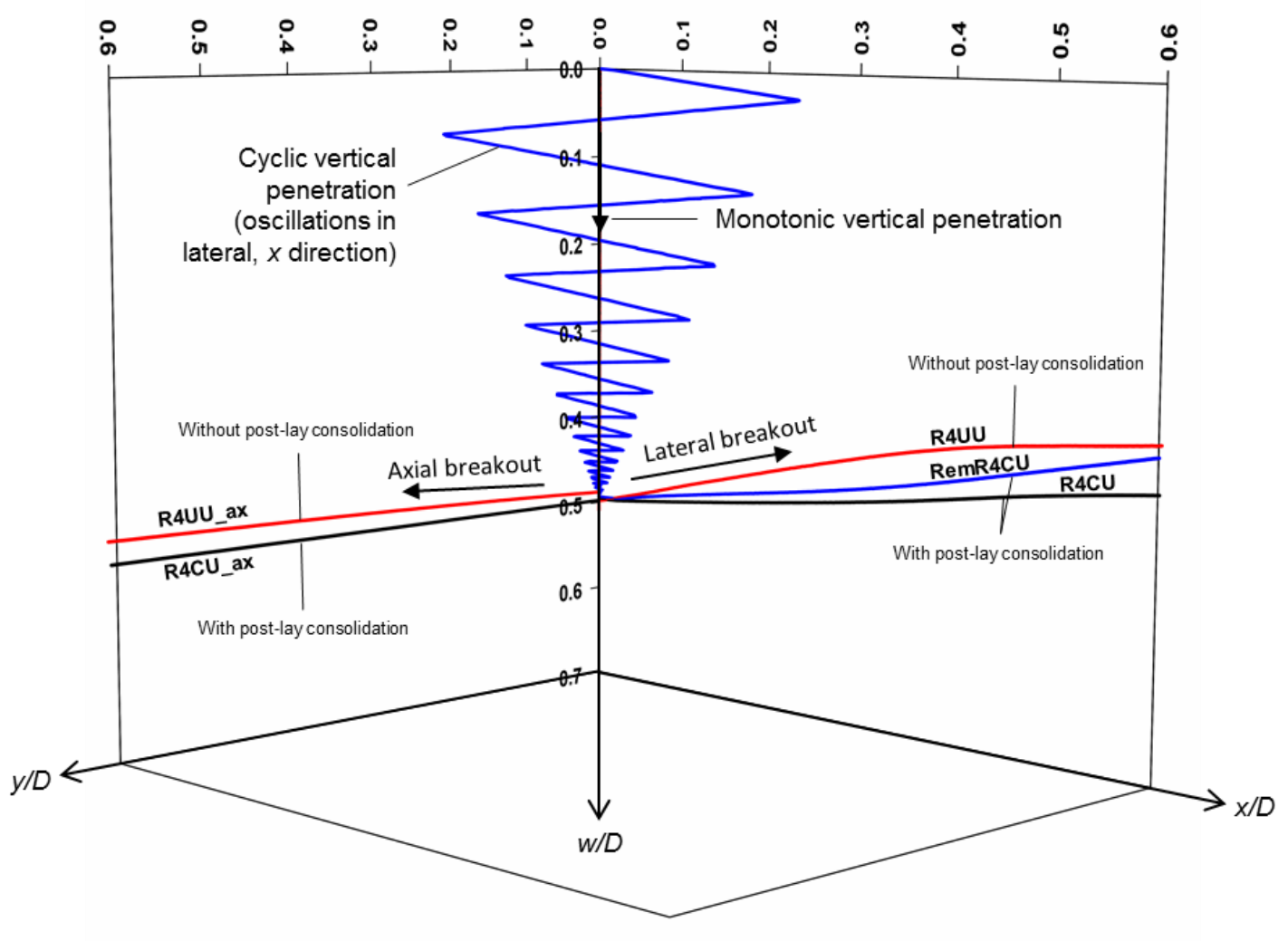




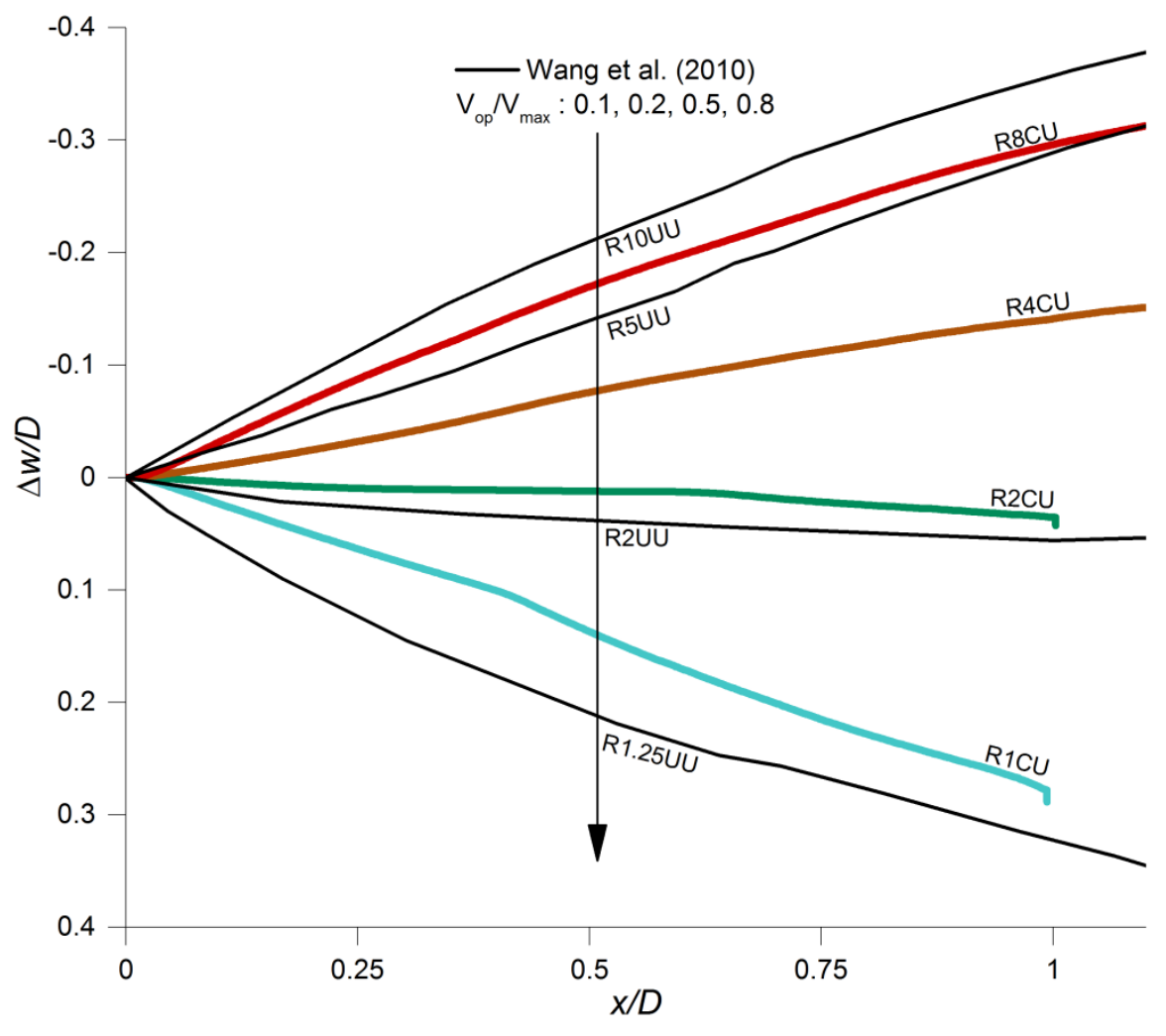

Figure 13 Effect of pipe weight on the pipe trajectory during lateral breakout 


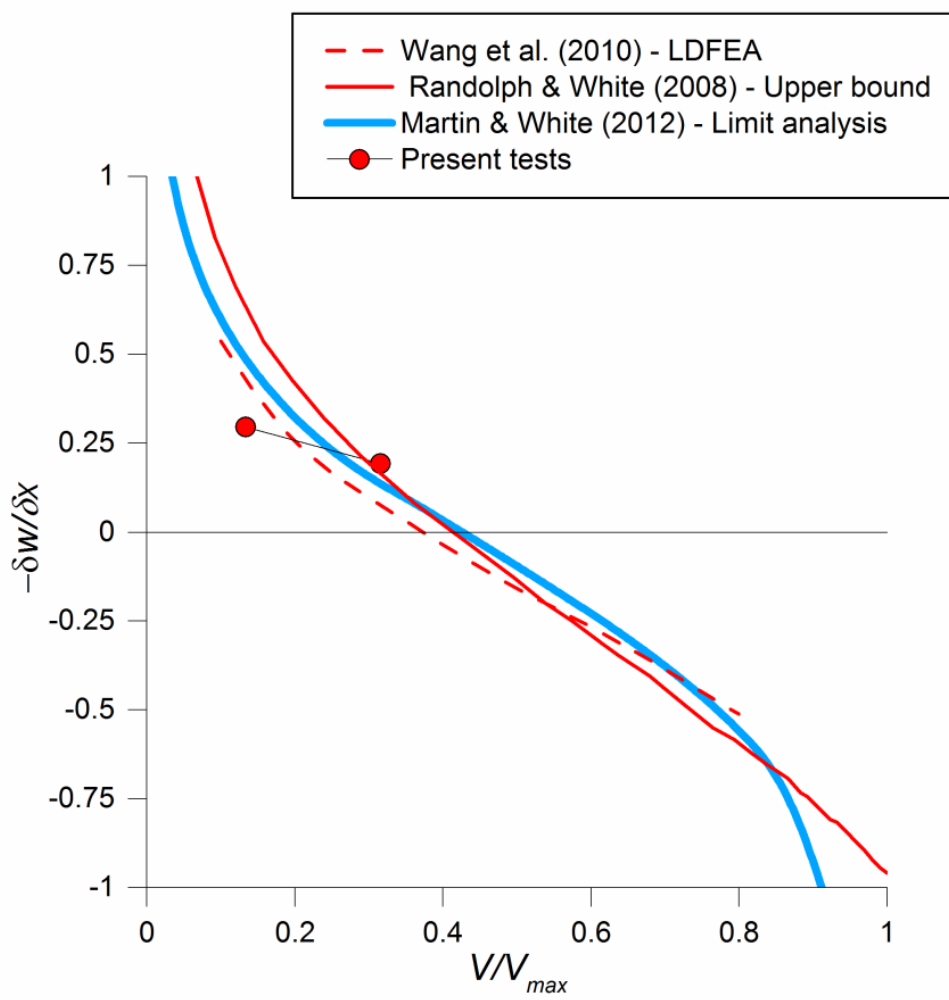

(a)

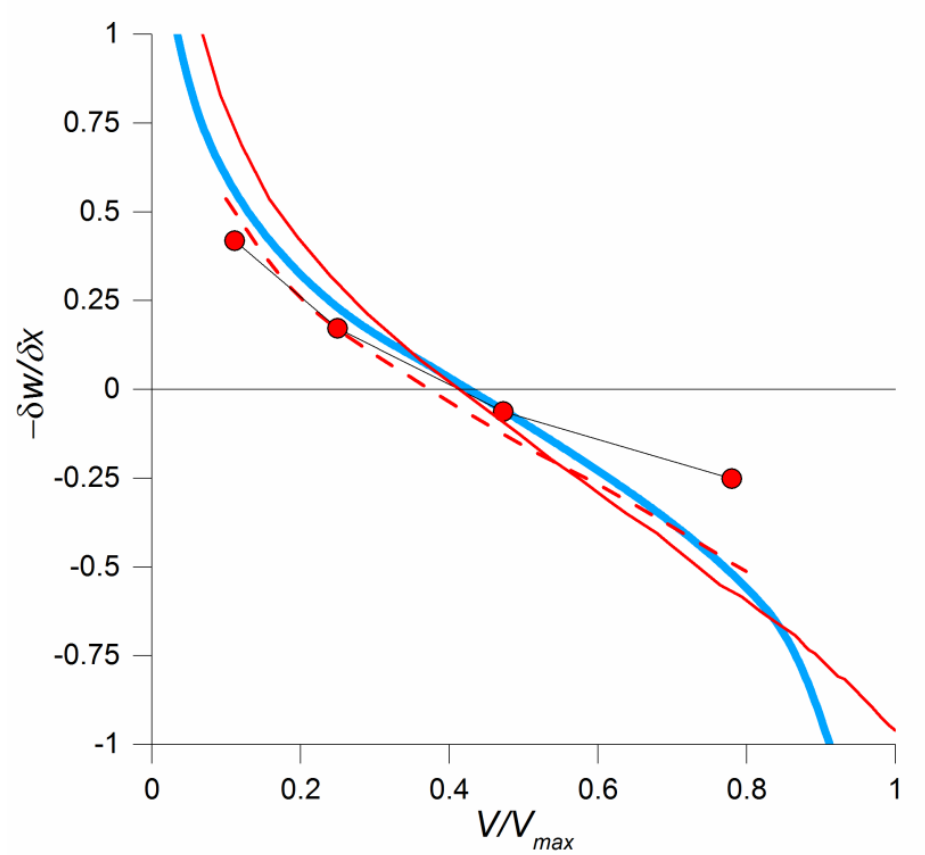

(b)

528 Figure 14 Inclination of displacement paths at lateral breakout compared against existing 529 solutions, shown for: (a) cases without post-lay consolidation, and (b) cases with post-lay 530 consolidation 